\title{
Design and Research Sowing Devices for Aerial Sowing of Forest Seeds with UAVs
}

\author{
Mikhail Lysych ${ }^{1, *(\mathbb{D})}$, Leonid Bukhtoyarov ${ }^{1}$ and Denis Druchinin ${ }^{2}$ \\ 1 Engineering Center, Voronezh State University of Forestry and Technologies Named after G.F. Morozov, \\ 8, Timiryazeva, 394087 Voronezh, Russia; vglta-mlx@yandex.ru \\ 2 Department of Forestry Mechanization and Machine Design, Voronezh State University of Forestry and \\ Technologies Named after G.F. Morozov, 8, Timiryazeva, 394087 Voronezh, Russia; \\ druchinin.denis@rambler.ru \\ * Correspondence: miklynea@yandex.ru
}

Citation: Lysych, M.; Bukhtoyarov, L.; Druchinin, D. Design and Research Sowing Devices for Aerial Sowing of Forest Seeds with UAVs. Inventions 2021, 6, 83.

https://doi.org/10.3390/

inventions6040083

\section{Academic Editors:}

Francisco Manzano Agugliaro and Konstantinos G. Arvanitis

Received: 28 September 2021

Accepted: 4 November 2021

Published: 10 November 2021

Publisher's Note: MDPI stays neutral with regard to jurisdictional claims in published maps and institutional affiliations.

Copyright: (C) 2021 by the authors. Licensee MDPI, Basel, Switzerland. This article is an open access article distributed under the terms and conditions of the Creative Commons Attribution (CC BY) license (https:/ / creativecommons.org/licenses/by/ $4.0 /)$.

\begin{abstract}
Modern unmanned aerial vehicles (UAV) can be effectively used for aerial sowing of forests. A feature of aerial sowing is the possibility of rapid reforestation at low costs, which is extremely important in the current environmental situation. The purpose of this study is to develop a set of sowing devices intended for use with UAVs. For this, the metering devices and seed distribution devices were analyzed, used on the UAV or having prospects for such use. The existing studies of metering devices, implemented by numerical methods, are analyzed. Further, the synthesis of eight different designs of sowing devices in the 3D CAD was carried out and their comparative assessment was completed in terms of mass and a set of technological parameters. Based on its results, a sowing device was selected that is most suitable for a specific given technology. Discrete Element Method (DEM) was used to simulate the workflow: imitation of loading of the sowing device, study of work in various modes, study of the process of impact interaction of seeds with the soil environment. The complex of developed sowing devices can provide sowing of almost any type of forest seeds within the framework of various technologies and soil climatic conditions.
\end{abstract}

Keywords: aerial sowing; sowing device; UAV; design; 3D CAD; DEM; modeling

\section{Introduction}

Currently, an increasing number of researchers are turning to the topic of reforestation using aerial sowing. The revival of interest in this topic is associated with an increase in the rate of deforestation and serious climatic changes, as well as the intensive development of unmanned aerial vehicles.

Only in recent decades, climate change on Earth has led to the emergence of a whole range of new threats and problems for various regions and countries. It is expressed in an increase in the average annual temperature, an increase in the concentration of carbon dioxide in the atmosphere, a change in the precipitation regime and an increase in the frequency of extreme weather events such as floods, droughts and hurricanes.

It is climate change that causes the greatest environmental damage, which inevitably affects the life and health of people, the state of flora and fauna, and in some regions becomes a tangible threat to the well-being of the population and sustainable development.

The most effective way to combat climate change is to maintain and systematically increase the area and quality of forests. Trees are the ones that can most effectively store carbon by neutralizing the "carbon footprint" of modern society.

At the moment, research is being initiated around the world to create carbon polygons and scale them to the level of carbon farms. However, the transition to the creation of carbon farms, as well as effective reforestation and the promotion of natural reforestation is impossible without a modern complex of reforestation technologies and monitoring using UAVs. 
The main advantages of using UAVs are the possibility of reforestation of hard-toreach and difficult-to-pass areas (including burnt areas and swampy areas), as well as high technology productivity with relatively low labor and material costs. In addition, the use of environmentally friendly and low-energy-consuming aerial sowing can significantly reduce $\mathrm{CO}_{2}$ emissions in comparison with classical reforestation technologies. The use of aerial sowing allows to reduce the use of energy-intensive operations performed by tractor equipment, such as: clearing areas and uprooting stumps; plow soil preparation; mechanized planting of artificially grown seedlings; performing agrotechnical care in the first years of life. Therefore, wherever the soil and climatic conditions allow, the use of aerial sowing will be effective, especially in difficult and remote areas $[1,2]$.

In accordance with silvicultural recommendations in Russia, aerial sowing can be used on burnt forests with sandy loam and well-drained loamy soils, where the fire caused complete burning of the forest floor, as well as on transport-remote forest areas where there is no possibility of year-round travel [3].

Aerial sowing technology is also used in the field of agriculture and gives the greatest efficiency in areas where the use of ground equipment is difficult. These are, first of all, areas with difficult terrain and low bearing capacity of soils. An example is sowing on steep slopes and early sowing of small-seeded cold-resistant crops, as well as early spring feeding of winter crops with mineral granular fertilizers [4].

The main actual problem of introducing aero sowing with the use of UAVs is the limited number of specialized sowing devices adapted for use with UAVs. At the same time, the existing designs of sowing devices used for ground seeders cannot be installed on UAVs, since they have a number of inappropriate parameters.

\section{Materials and Methods}

\subsection{Existing Types of Sowing Devices}

Sowing units usually have two main systems-a metering system and a seed distribution system. In addition, many designs have an additional system - a system for ensuring a stable supply of seeds from the hopper. It can be mechanical [5] or vibration [6].

Let us consider the main types of seed metering and distribution systems used on UAVs or having prospects for such an application.

\subsubsection{Metering Systems}

Seed meter are devices that dosed seeds from the seed hopper and place them in the distribution system mechanisms that assist in moving the seed from the metering device to the ground.

The main functional requirements for seed metering devices are:

- $\quad$ dosing of seeds at a predetermined rate (for example, $\mathrm{kg}$ or the number of seeds per running meter);

- dosing of seeds with the required accuracy (interval) in accordance with the sowing scheme (for example, row sowing, sowing by quad groups);

- $\quad$ minimal damage to the seed during metering.

Let's consider the main types of metering devices that can be used in sowing devices for UAVs (Figure 1). Two different groups can be distinguished here: mass flow metering devices (periodically or stationary opening metering devices, fluted roller metering devices) and precision seed metering devices (vacuum disc precision metering devices, mechanical vertical plate precision metering devices, vacuum vertical plate precision metering devices).

The simplest mass flow metering device is the stationary open type. In a stationary open device, the sowing rate is regulated by changing the size of the throughput using a movable flap.

The periodically opened type has a drive that allows to change the size of the hole directly during operation. It is also possible to feed in portions, carried out by periodically opening and closing the metering device. 


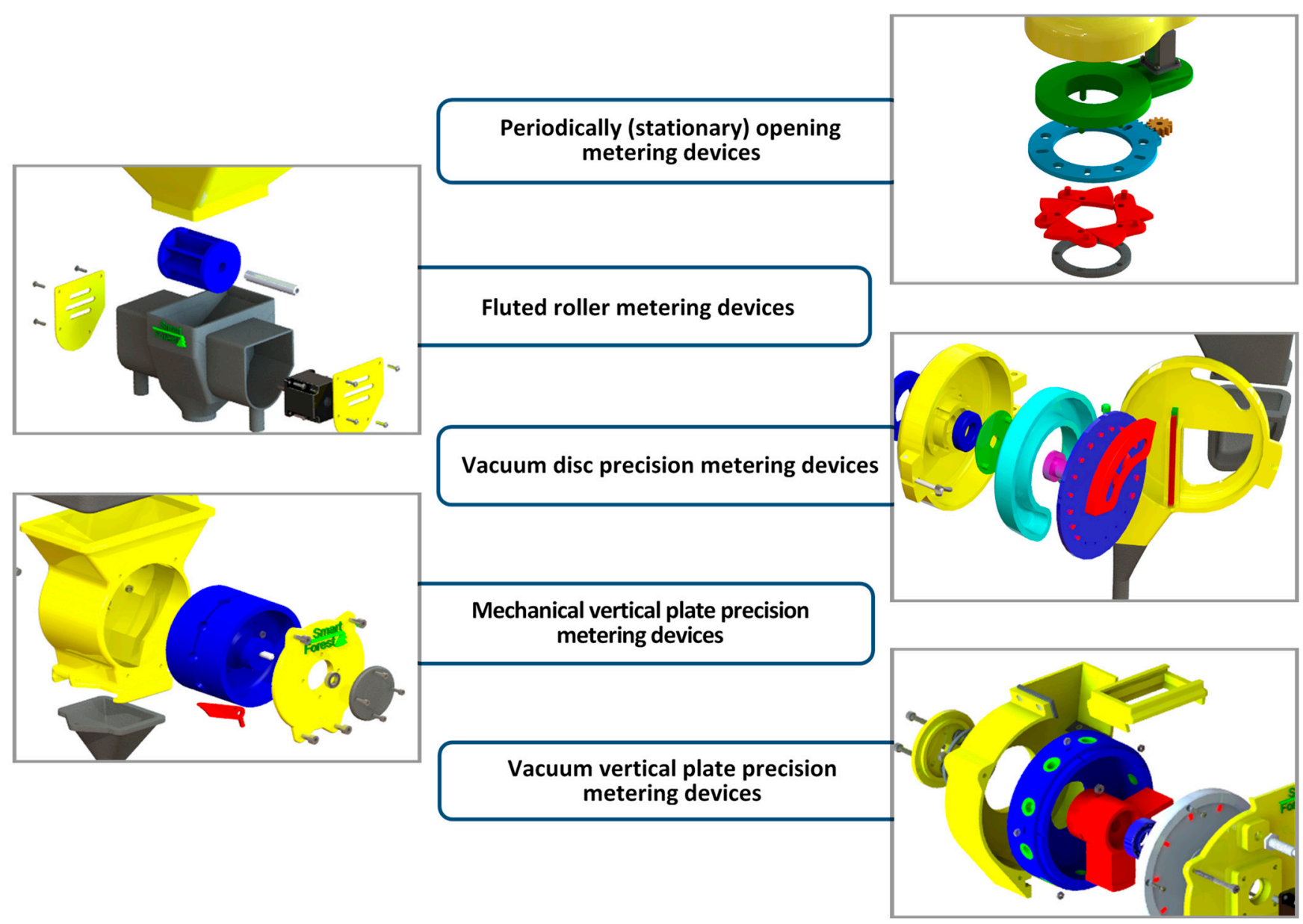

Figure 1. Metering mechanisms of sowing device.

An example is the metering mechanisms of the sowing device for the UAV Drone Granula Spreadying System from Shenzhen GC Electronics Co., Ltd. [7]. A trapezoidal hole with a sliding flap is used here.

In the design of the UAV seeder developed within the framework of the Dronecoria project, a central shutter mechanism is used, which has a high operating speed and, when opened, forms an almost round hole [8].

The mass flow fluted roller metering devices has found wide application in agriculture due to its simplicity and high reliability. It is widely used in fertilizer applicators and seeders. It can have roller of various shapes (fluted, spiral, peg, studded) [9].

The fluted roller metering devices is used in the XAG JetSeed pellet spreading system designed for installation on UAVs [5].

The vacuum disc precision metering devices is widely used in agriculture. At the moment, this type has not found application for aero sowing from unmanned aerial vehicles. This is due to the following main reasons: the need to create a vacuum, which is difficult to ensure when installed on a UAV; the difficulty of providing additional acceleration of the seed; restrictions on the size and shape of seeds.

The mechanical vertical plate precision metering devices is also widely used in agriculture [9]. Its distinctive feature is the absence of the need for a vacuum, which greatly simplifies the design and reduces weight with a slight decrease in accuracy and seeding speed.

The vacuum vertical plate precision metering devices, such as a vacuum disc precision metering device, allows you to achieve high accuracy in dosing seeds. At the same time, its design allows for the supply of compressed air from the inner side of the drum for additional acceleration of the seed. 
None of the metering devices can meet all the sowing requirements of various forest species, the seeds of which are very different in size and shape. Therefore, it is necessary to use several types of metering devices adapted to specific types of forest seeds.

\subsubsection{Seed Distribution Systems}

Seed distribution systems include devices that assist in moving seed from the meter to the ground.

Basic functional requirements for seed distribution systems:

- $\quad$ stable transfer of seed from the unloading point of the seed meter to the ground surface;

- $\quad$ ensuring the accuracy of distribution (distance between seeds) when they are laid on the soil surface;

- providing (if necessary) additional acceleration of seeds to penetrate into the surface layer of the soil.

Consider the main types of distribution systems used in sowing devices for UAVs (Figure 2).

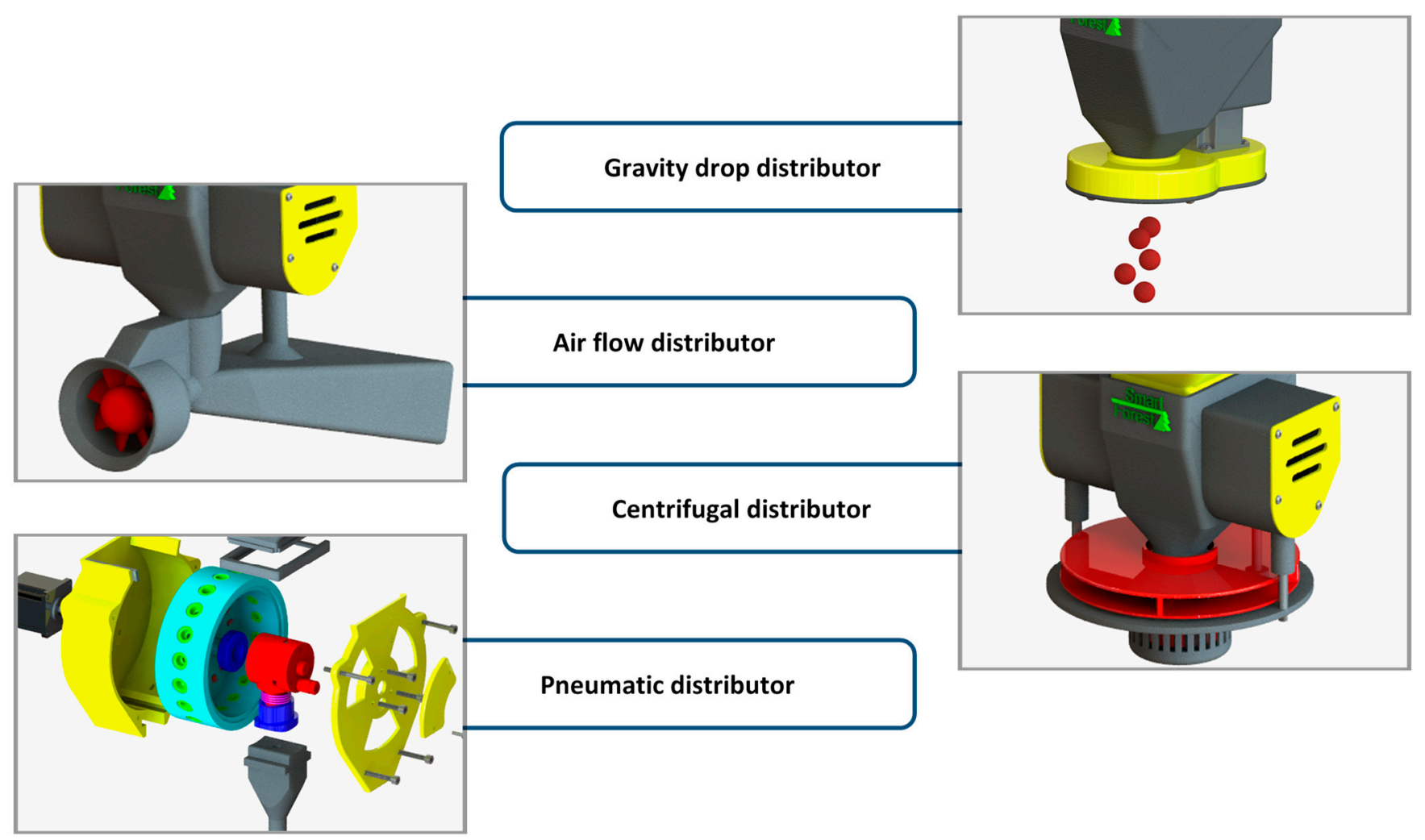

Figure 2. Seed distribution mechanisms.

In the gravity drop distribution device, seeds simply fall from the seed meter onto the soil surface. The process takes place only under the influence of gravitational forces. This principle is used on all sowing device that do not have a distribution mechanism module. Additionally, the simplest guides can be used that slightly change the trajectory of their movement.

Air flow distributors with forced high-speed air flow are used to improve the quality of seed distribution. This method can significantly improve the uniformity of seed distribution over the area without causing damage.

A similar design solution is used in the XAG JetSeed pellet spreading system [5]. Eight duct fans are used, producing high-speed, focused airflows up to $18 \mathrm{~m} / \mathrm{s}$. 
The air sowing system for rapeseed [10] uses air flow distribution mechanism which is a miniature version of the distributor used in land seeders. The working width is $2.1 \mathrm{~m}$, the maximum working speed is $8 \mathrm{~m} / \mathrm{s}$. The sowing device weighs about $3 \mathrm{~kg}$, and the payload is $5 \mathrm{~kg}$ of rapeseed.

The centrifugal distributor is widely used in sowing devices and fertilizer spreaders installed on UAVs. It has a fairly simple design and allows the spread of seeds at a distance of 5 to $20 \mathrm{~m}$. The size of the seeds used is usually limited to a diameter of $0.5-5 \mathrm{~mm}$.

The UGS-2G pellet spreader from CFR-Innovations is specially designed for use with unmanned aerial vehicles. Its total weight is $1148 \mathrm{~g}$ with a capacity of $8 \mathrm{~L}$. The adjustable spread width is from 2 to $23 \mathrm{~m}$, the flow rate is from 1 to $12 \mathrm{~L} / \mathrm{min}$ [11].

The T Series Spreading System 2.0 was developed by DJI and is compatible with the DJI Agras T16 or T20 UAVs platforms [12]. The size of the materials is from 0.5 to $5 \mathrm{~mm}$, the volume of the hopper is $20 \mathrm{~L}$. The feed rate is controlled by the built-in agitator and outlet hole. The optimum spreading range is 5 to $7 \mathrm{~m}$.

The sowing complex OSA HEXA S-1 with a centrifugal spreader is manufactured by the Russian company Bozon Aero [13]. It is designed for automated sowing of seeds, spreading of granular fertilizers and other substances. The hopper capacity is $9 \mathrm{~L}$ and the maximum payload is up to $10 \mathrm{~kg}$. Spreading width 4-6 $\mathrm{m}$ (depending on flight height).

Pneumatic distributors are also widely used for aerial sowing of forest seeds. Their main distinguishing feature is giving additional acceleration to the pelleted seed for its penetration into the surface layer of the soil. This improves the survival rate of seeds and ensures high accuracy of their location.

The pneumatic sowing system from AirSeed Technologies is capable of shooting two pelleted seeds per second at a speed of 150 to $300 \mathrm{~m} / \mathrm{s}$ [14]. The sowing module can be attached to the bottom of various drone models. According to preliminary estimates, a two-man team operating two machines can plant up to 40,000 seeds per day.

Similar pneumatic seed acceleration systems are used in the design of the sowing device from Dendra Systems [15], DroneSeed [16] and Flash Forest [17].

\subsection{The Main Seeding Material Used for Aerial Sowing}

The design of any sowing device is determined by the properties of the seed. Let us analyze its main types used for aerial sowing. Let us first consider seeds in their natural form without additional artificial cover.

By size, seeds are subdivided:

- $\quad$ small (spruce, pine, birch);

- $\quad$ medium (cedar, fir, viburnum, linden);

- $\quad$ large (oak, hazel, hazelnuts, walnuts).

In shape, seeds are:

- $\quad$ spherical (linden, hazel, hazelnuts, walnuts);

- $\quad$ ellipsoidal (spruce, pine, oak, cedar);

- flat (yellow acacia).

Figure 3 shows seeds of various size groups and breeds typical for the Central Black Earth Region of Russia. These models were performed using methods similar to those presented in previous studies by the authors [18].

Aerial sowing with the use of UAVs is now more often performed with seeds in artificial covers (Figure 4). They often have the correct spherical shape and slight dimensional deviations (Figure 4a). This facilitates the work of precision sowing device with additional pneumatic seed acceleration. A similar type of pelleted seeds is used in forest sowing complexes by Dendra Systems [15], Flash Forest [17] DroneSeed [16] and AirSeed Technologies [14]. Their feature is the high requirements for the strength of the artificial covers, which should not be damaged by impact interaction with the soil. 


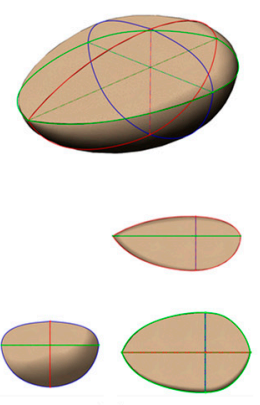

(a)
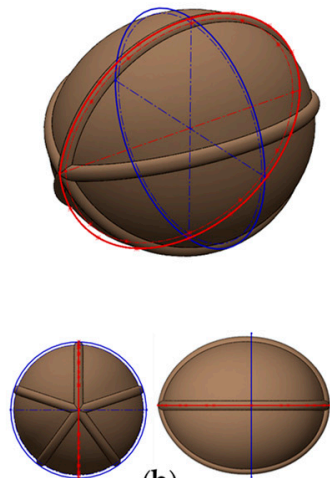

(b)
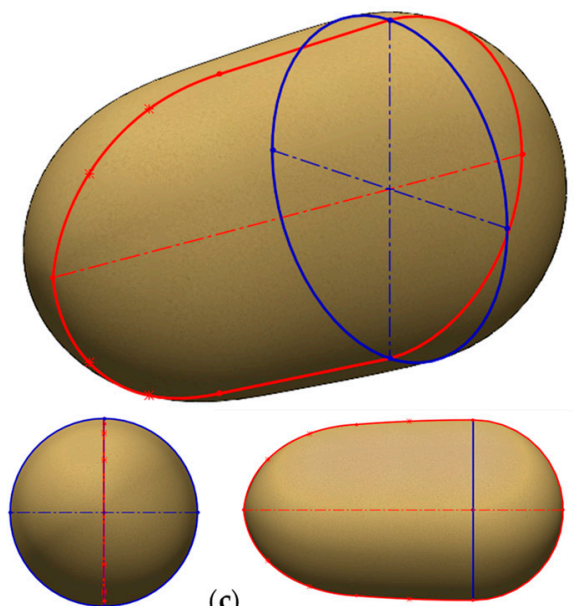

(c)

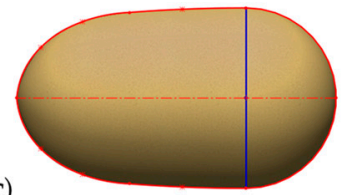

Figure 3. Natural seeds of various size groups: (a) Small ellipsoidal Scots pine (Pinus sylvestris); (b) Medium spherical European linden (Tilia europaea); (c) Large ellipsoidal Pedunculated oak (Quercus robur).

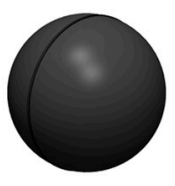

(a)

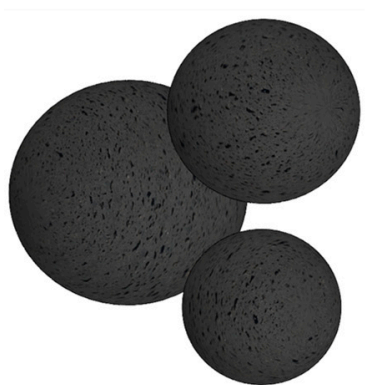

(b)

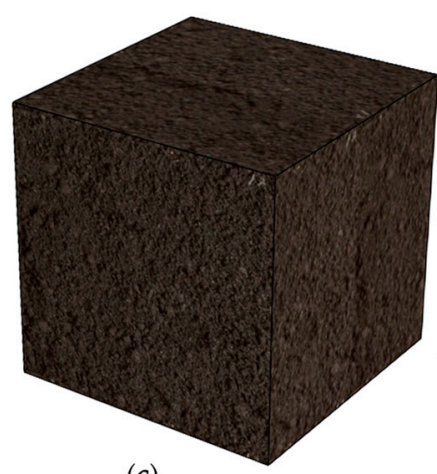

(c)

Figure 4. Pelleted and briquetted seeds: (a) Calibrated spherical pelleted seed; (b) Uncalibrated spherical or ellipsoidal pelleted seed; (c) Square briquetted seed.

Additionally used are uncalibrated forest granulated seeds, which are close to spherical in shape, but have significant differences in size (Figure $4 \mathrm{~b}$ ). Airflow and centrifugal sowing device are widely used for spreading small to medium sized seeds in agriculture. These are the sowing device JetSeed from XAG [19], UGS-2G from CFR-Innovations [11], T Series Spreading System 2.0 from DJI [20] and OSA HEXA S-1 company Bozon Aero [13]. Sowing large seeds can be carried out periodically opening gravitational metering devices. These are sowing complexes of the Dronecoria project [8] and new sowing device from Flash Forest [17].

Square briquetted seeds can be effectively used on slopes as they are not susceptible to rolling and have a large contact area with the soil surface (Figure 4c). They are usually quite large and of limited strength. For sowing, gravitational periodically opened mechanisms are used, for example, modern sowing complexes from DroneSeed [21].

For sowing natural seeds, similar types of metering device can be used, selected according to the size of the seeds. Exceptions are precision sowing units with additional pneumatic seed acceleration, which require an exact spherical seed shape.

\subsection{Existing Methods of Simulating Sowing Device}

At the moment, the main method for creating technical objects is parametric 3D modeling using 3D CAD programs and software for engineering calculations (CAE). This method allows to develop not only a well-thought-out concept, but also to carry out a study of mass-inertial characteristics. This is extremely important for equipment installed 
on UAVs, which have strict weight restrictions. In this work, we used CAD SOLIDWORKS 2021.

For simulation studies of sowing devices at the moment, the most commonly used numerical method is the discrete element method (DEM) (Figure 5). It allows to effectively simulate the processes of interaction of the elements sowing device with an almost unlimited number of seeds of various shapes. In this case, the laws of interaction of seeds with each other and with the elements of the sowing device, as well as the strength parameters of seeds and their covers, can be taken into account. To do this, they are represented as a collection of related discrete elements. Let us briefly consider the existing studies of various sowing device carried out by DEM methods.

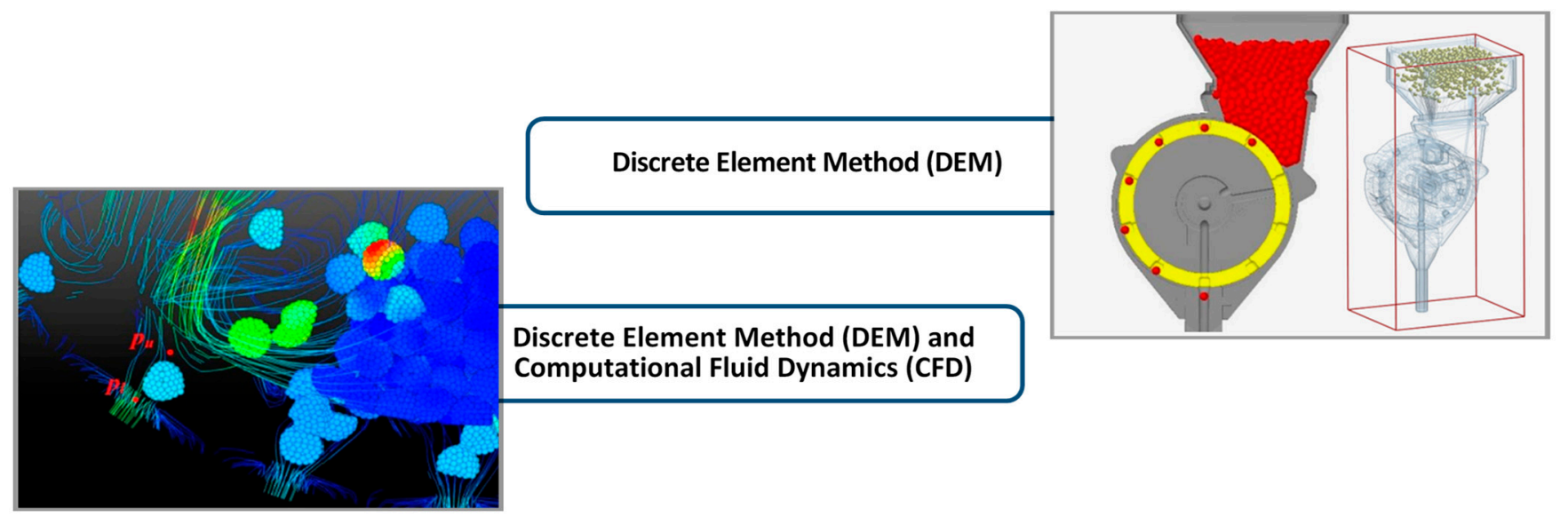

Figure 5. Simulation of the working process of sowing device using numerical methods.

A large number of researchers studied the working process of fluted roller metering devices and similar fertilizer dispensers [22-24]. The main difference between the studies is the use of different types of metering rolls and seeds of different geometric shapes.

There are also a lot of works devoted to the study of centrifugal sowing devices by the method of discrete elements [25-27]. However, they are devoted to modeling tractor spreaders and there are practically no studies of spreaders intended for installation on UAVs [25], although this class of devices is now being intensively developed.

A number of works [28-33] are also devoted to the study of agricultural mechanical sowing device of drum, disc, and spoon types by the method of discrete elements.

Computational fluid dynamics (CFD) can be used with discrete element method (DEM). The combined application of these methods allows one to reliably investigate the working processes of sowing device with air-blowing [34,35], as well as distribution mechanisms, primarily the air flow distribution mechanism [36]. In addition, the method of computational fluid dynamics can be used to study the process of falling seeds, taking into account the properties of the air environment and air flows created by drone propellers.

Analysis of the research led to the following conclusions:

- $\quad$ DEM modeling can be successfully applied to study the working processes of periodically (stationary) open metering device, fluted roller device, mechanical vertical plate precision device, centrifugal spreaders and other similar mechanical types;

- collaborative DEM-CFD modeling allows to reliably investigate the operation of various vacuum metering device, air-blowing device, air flow distributors and pneumatic distributors.

At the same time, according to the data of experimental checks carried out in the studies considered, the discrepancies with the simulation results are no more than 10-15\%.

To study the processes of interaction of soil with seeds and working organs, the method of discrete elements is also increasingly used (Figure 6). The following groups of studies can be distinguished. The most significant group is the study of the interaction of 
passive working organs with the soil environment [37]. Quite a lot of works devoted to the study of the interaction of active working organs with the soil $[38,39]$. There are also separate studies modeling the interaction of seeds and soil $[40,41]$, fertilizer granules and soil [42].

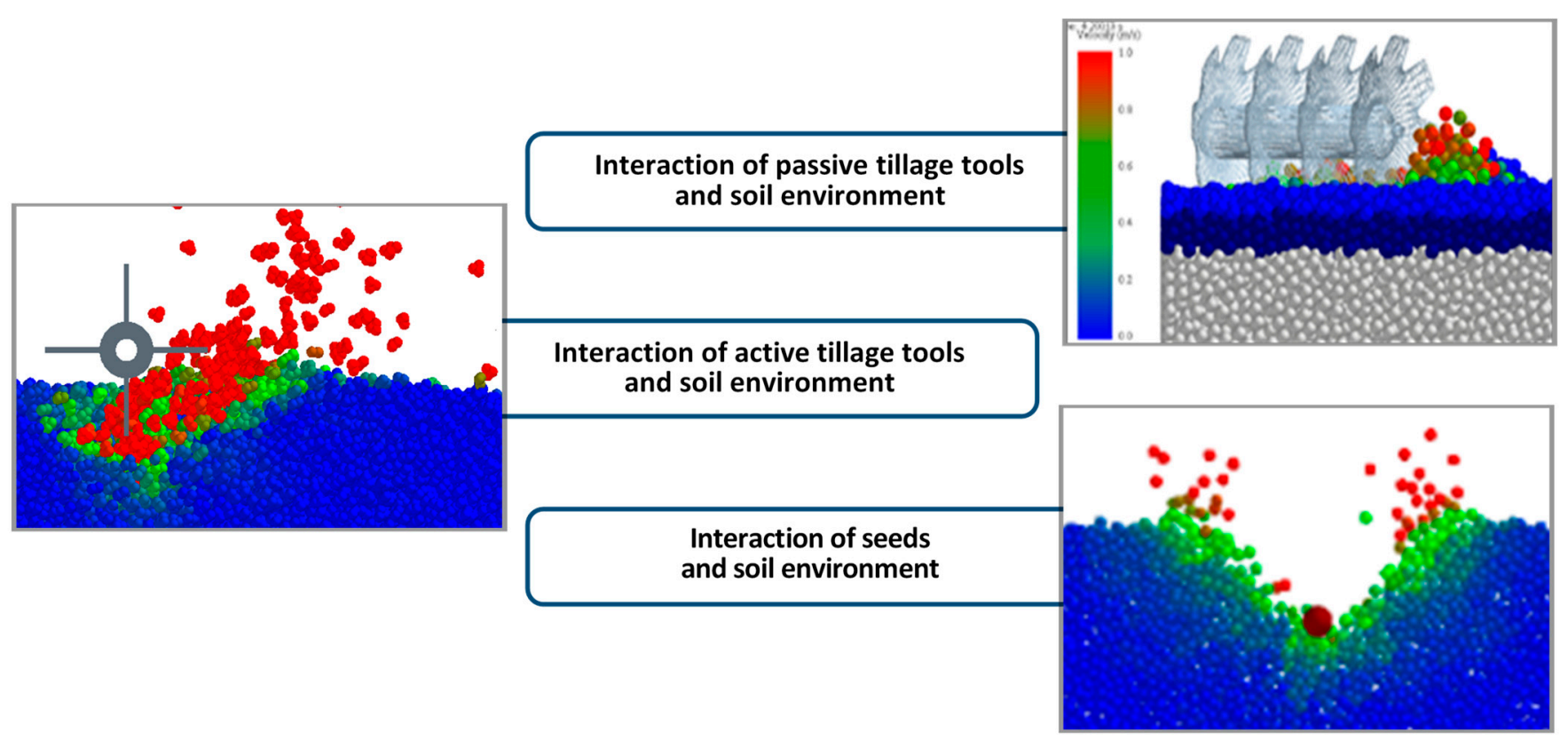

Figure 6. Simulation of interaction with the soil environment by the DEM.

Studies of the processes of impact interaction of seeds with soil media are practically absent due to the relative novelty of this direction. In other industries there are similar studies of the impact interactions of objects with granular media, for example, the processes of formation of craters on the surface of planets, the movement of projectiles in granular media, etc. This is a series of experimental studies [43-46] and numerical studies using DEM modeling [47-49]. Comparison of the parameters obtained as a result of DEM modeling with experimental data has proven that they are in fairly good agreement with each other. However, the results of these studies cannot be used to describe the processes of impact interaction of seeds with the soil environment due to significant differences in the properties of the environments and modes of interaction.

\section{Results and Discussion}

\subsection{Conceptual Synthesis of Designs of Sowing Device for UAVs in a 3D CAD}

Based on the performed constructive analysis of metering systems and seed distribution systems, eight different designs of sowing device designed for comparative studies were synthesized in 3D CAD SOLIDWORKS.

Table 1 shows 3D models of mass flow sowing devices in isometric view, with spaced parts and three projections (side, front, bottom). 
Table 1. Sowing device for flow sowing.

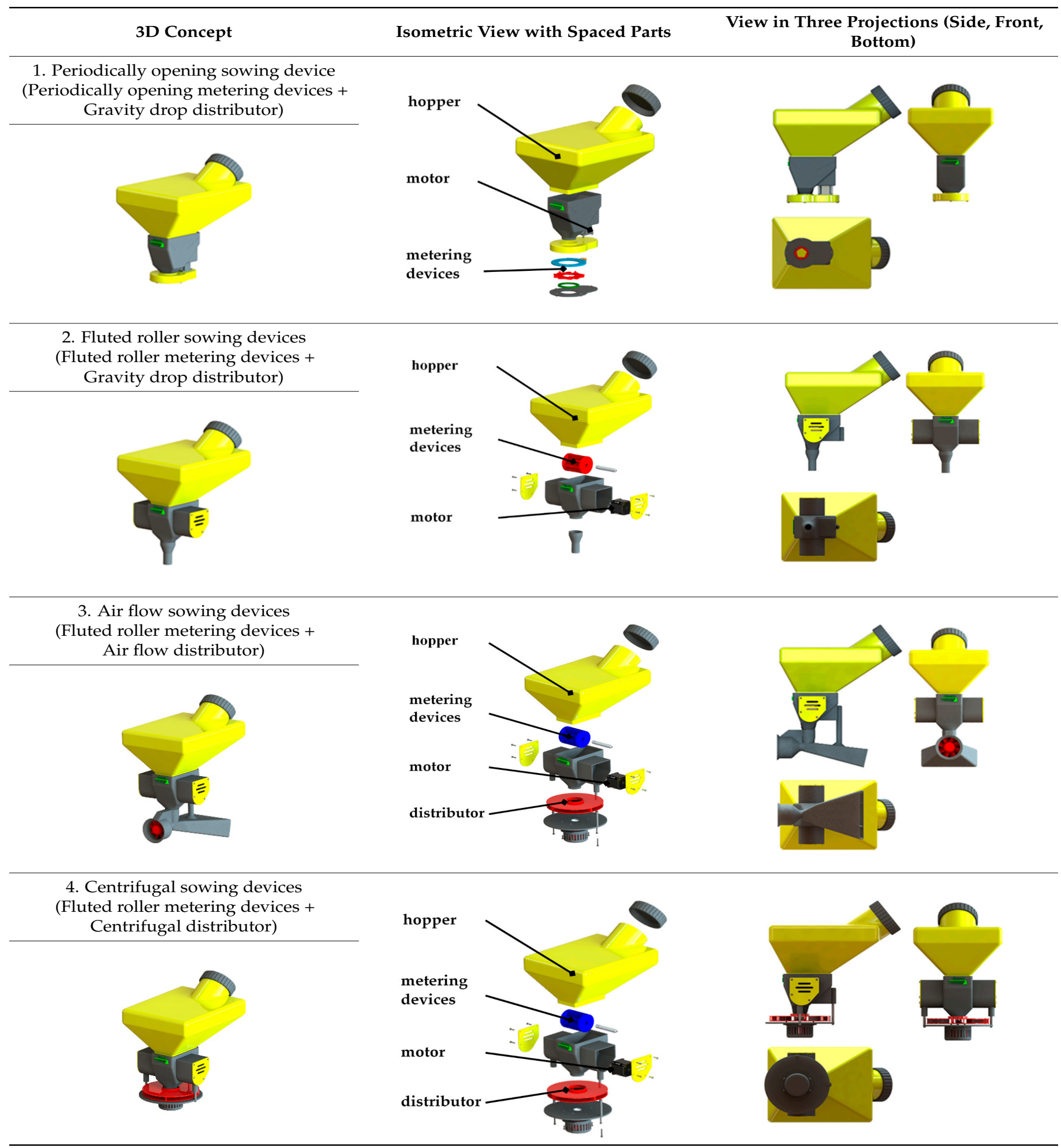

Concept 1 used central shutter mechanism has a high speed of action and in the open state forms an almost round hole. This enables batch feeding by periodically opening and closing the metering mechanism. Sowing material of various sizes and shapes can be used, including mixtures of seeds of different size groups. The uniformity of distribution is low and a mixing mechanism is required for poorly flowing seeds.

Concept 2 can be equipped with various types of rollers, which allows it to be used for sowing small and medium seeds. Provided that the mixing mechanism is installed, it 
can work even with unfinished seeds. Carries out row sowing with seed distribution only due to the forces of gravity and the movement of air masses. With a high simplicity and reliability of the design, it can cause damage to seeds and their artificial covers.

Concept 3, through the use of an air flow distribution mechanism, significantly improves the uniformity of distribution and the width of the sowing strip. At the same time, with an increase in the weight of seeds, the efficiency of distribution decreases markedly. Energy consumption and weight of the structure are increased due to the need to install an additional motor that creates an air flow in the distributor.

Concept 4 has a centrifugal distributor that ensures even distribution and significantly increases the width of the sowing strip. Energy consumption and weight of the constructions are also increased due to the installation of an additional motor that rotates the spreader disc.

Table 2 shows 3D models of precision sowing devices in isometric view, with spaced parts and three projections (side, front, bottom).

Table 2. Sowing device for precision sowing.

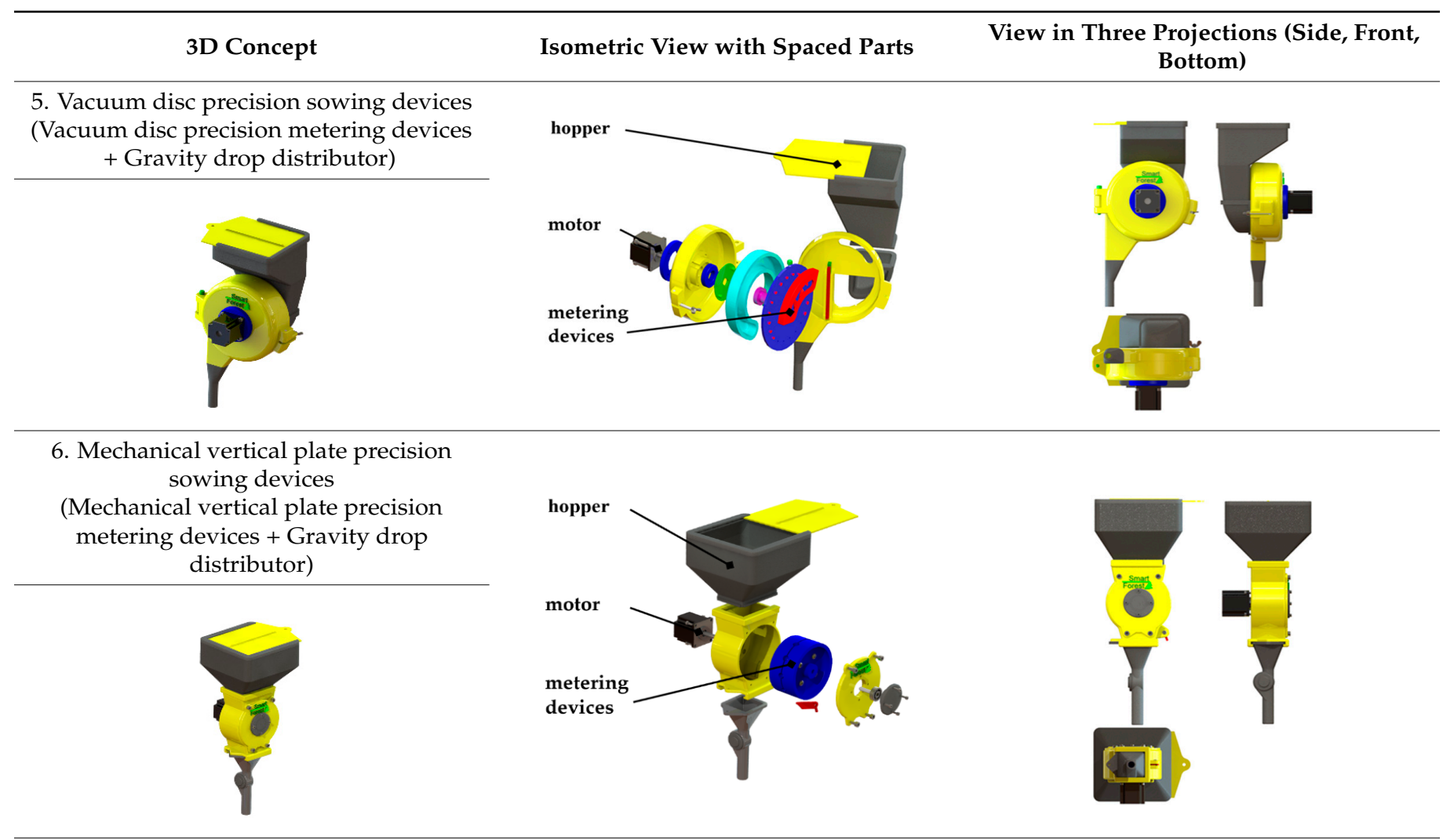

7. Mechanical-pneumatic vertical plate precision sowing devices

(Mechanical vertical plate precision metering devices + Pneumatic distributor)
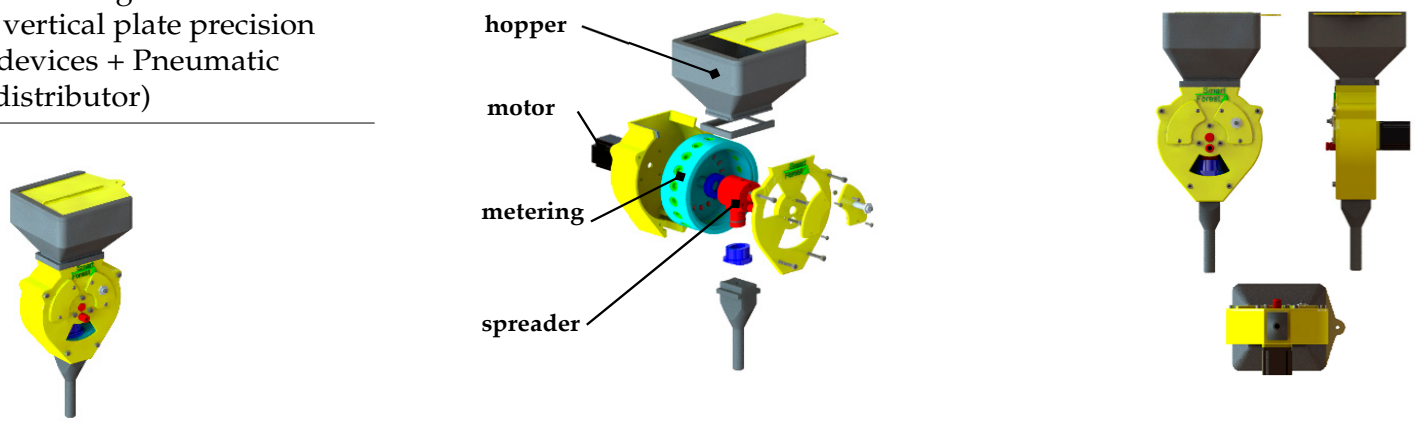
Table 2. Cont.

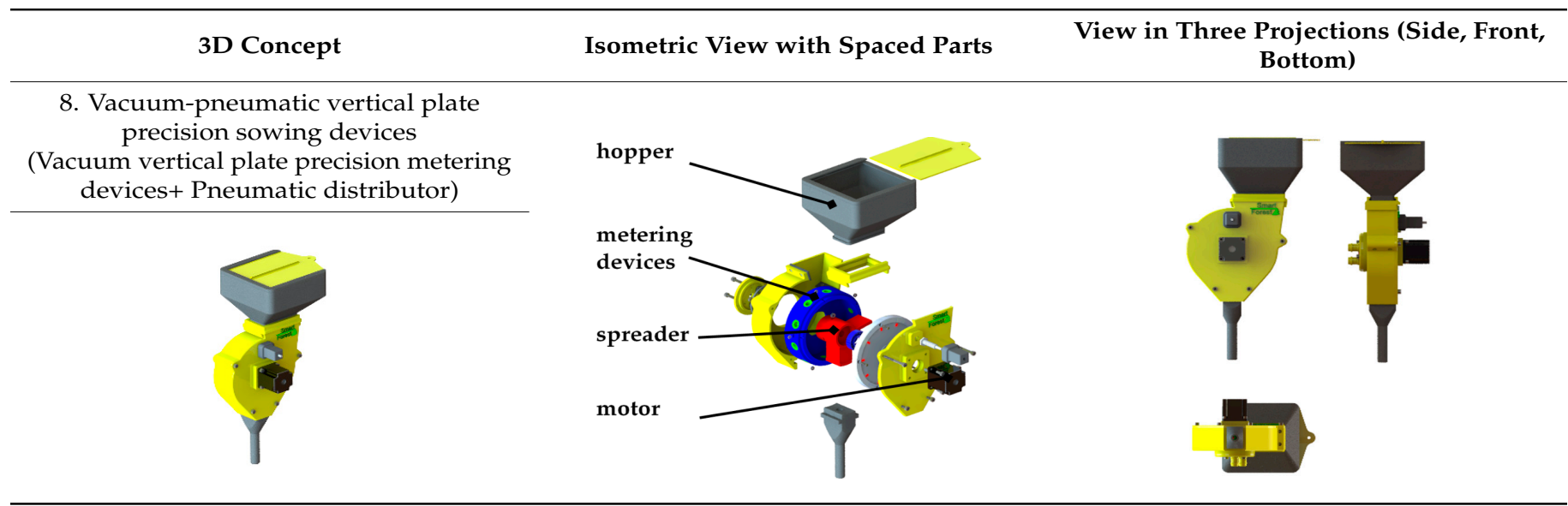

Concept 5 can be used for sowing small and medium-sized seeds that are sufficiently uniform in size. The main disadvantage is the need to create a vacuum, without which the construction becomes completely inoperative, as well as the complexity of additional acceleration of seeds.

Concept 6 has a simple and reliable design that does not require a vacuum. Has a wide range of sown seeds in size and shape. The distribution system is also gravitational.

Concept 7 differs in that it has a pneumatic system that gives the seeds the additional acceleration necessary to penetrate into the surface layer of the soil. The uniformity of seed distribution in the row also increases significantly. It is used only with special pelleted seeds of a spherical shape with slight deviations in size and shape.

Concept 8 has an optional vacuum seed capture system. This improves the uniformity of sowing. At the same time, in contrast to concept 5 , the sowing device remains operational even in the absence of a vacuum source, working similar to a sowing device 7 . It is also used only with special pelleted seeds of a spherical shape with a slight variation in size.

\subsection{Evaluation of Selected Design Solutions}

\subsubsection{Investigation of Mass Inertial Characteristics of Sowing Devices}

At this stage of modeling, the mass-inertial characteristics of the sowing devices were set by applying to them the properties of materials from the standard SolidWorks libraries. The study of mass-inertial characteristics is shown on the example of a vacuum-pneumatic vertical plate precision sowing devices (Figure 7).
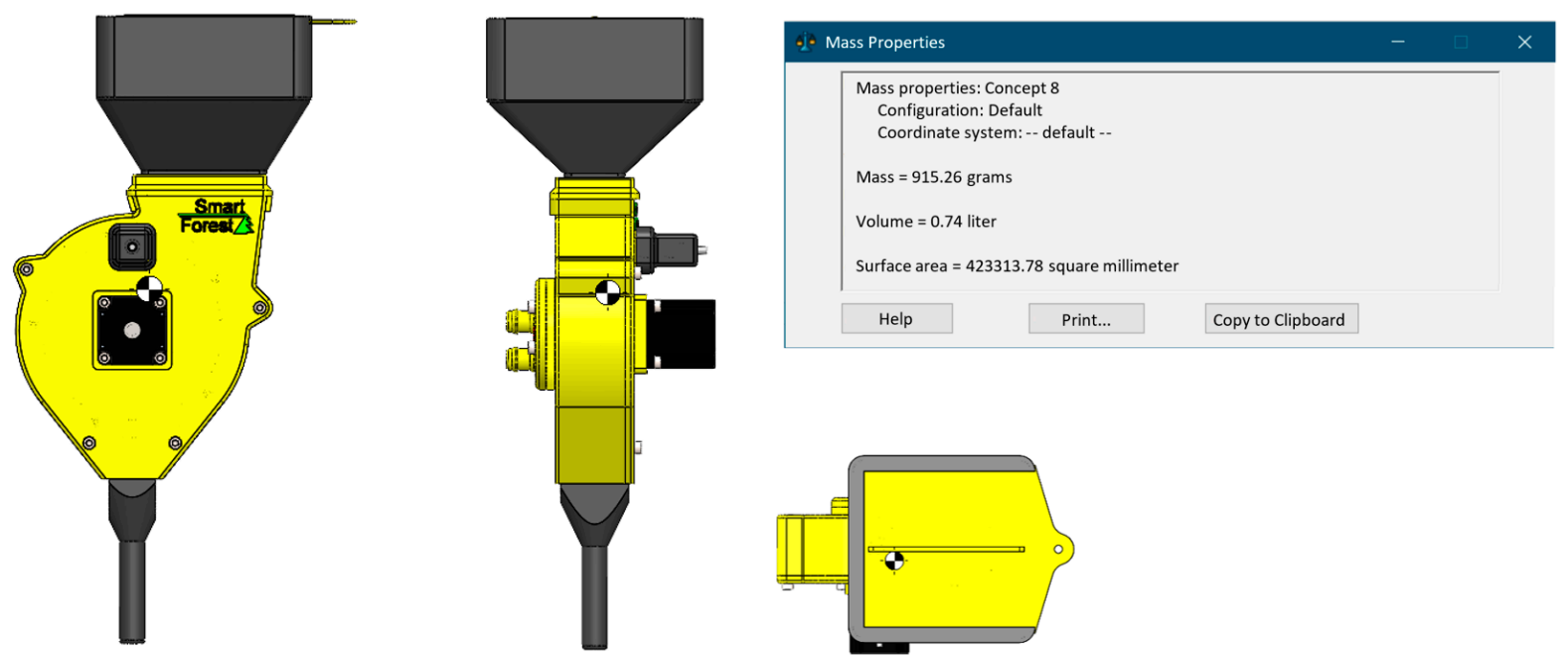

Figure 7. Investigation of mass-inertial characteristics of sowing devices. 
For preliminary determination of the payload, the internal volume of the hopper and the upper part of the throat of the sowing devices were calculated according to their 3D model. An example of determining the size of the payload is shown in Figure 8.
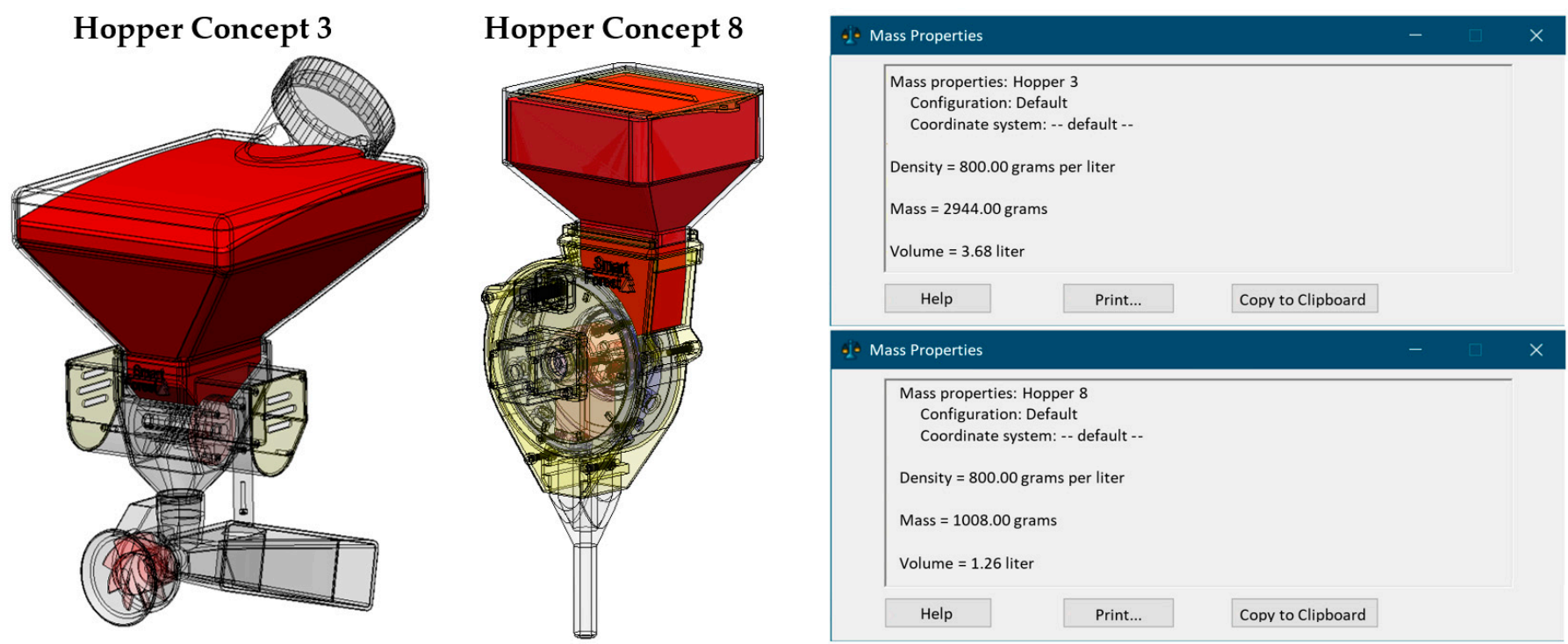

Figure 8. Determination of the payload of the sowing devices.

The payload of the seeds was calculated according to the obtained useful volumes of the sowing devices and the volumetric mass of seeds, taken equal to $800 \mathrm{~g} / \mathrm{L}$, which corresponds to the mass of high-density seeds.

In addition, when assessing the total mass of the sowing devices, the weight of additional batteries necessary to drive the metering mechanisms of all sowing devices $(200 \mathrm{~g})$ and the drive of the distribution mechanism in designs 3 and $4(300 \mathrm{~g})$, as well as the compressor in designs 5 and 8 ( $300 \mathrm{~g}$ ) were taken into account. Separately, the average mass of additional equipment was taken into account, including a compressor in designs 5 and $8(1000 \mathrm{~g})$, as well as a compressed air cylinder per $1 \mathrm{~L}$ in designs 7 and 8 (1000 g). The masses of energy sources and additional equipment were selected by the authors approximately.

Table 3 shows the weights of the individual components as well as the total mass of the sowing devices when fully loaded. This characteristic is the most important when choosing a UAV in terms of carrying capacity.

Table 3. Evaluation of various concepts by mass.

\begin{tabular}{ccccccccc}
\hline \multirow{2}{*}{ Criterion (Mass, $\mathbf{g}$ ) } & \multicolumn{7}{c}{ 3D Concept } \\
\cline { 2 - 10 } & $\mathbf{1}$ & $\mathbf{2}$ & $\mathbf{3}$ & $\mathbf{4}$ & $\mathbf{5}$ & $\mathbf{6}$ & $\mathbf{7}$ & $\mathbf{8}$ \\
\hline Sowing devices & 799 & 998 & 1201 & 1297 & 773 & 543 & 964 & 915 \\
\hline Payload & 3186 & 2944 & 2944 & 2944 & 920 & 946 & 952 & 1008 \\
\hline Additional batteries & 200 & 200 & 500 & 500 & 500 & 200 & 200 & 500 \\
\hline Additional equipment & - & - & - & - & 1000 & - & 1000 & 2000 \\
\hline Total mass & 4185 & 4142 & 4645 & 4741 & 3193 & 1689 & 3116 & 4423 \\
\hline
\end{tabular}

Analysis of mass characteristics showed that all sowing devices have a total mass of less than $5000 \mathrm{~g}$, which allows them to be used with the multicopter DJI SPREADING WINGS S1000+ (Figure 9), MATRICE 600PRO or any other similar in characteristics (flight time is at least $20 \mathrm{~min}$ with a payload of $5 \mathrm{~kg}$ ). According to our preliminary estimates, this flight time will be sufficient to carry out aerial sowing missions. 

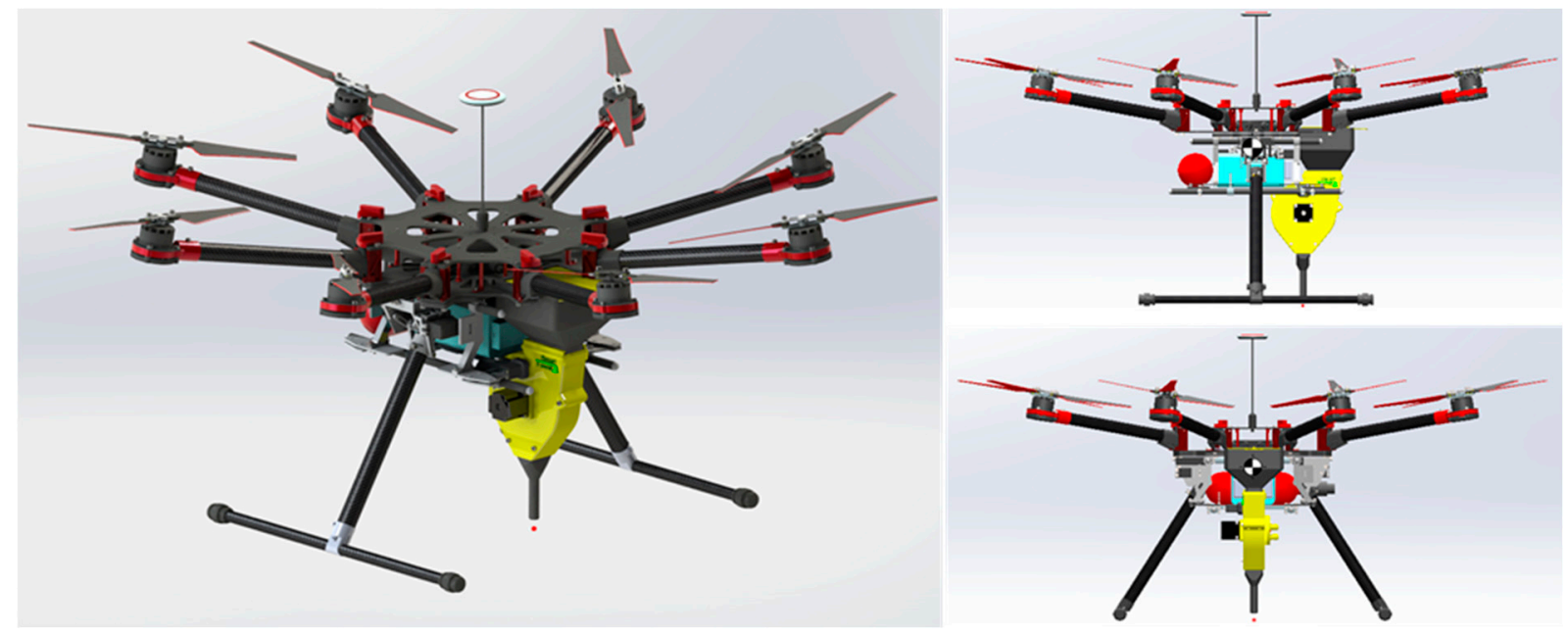

Figure 9. Layout of a vacuum-pneumatic vertical plate precision sowing devices and multicopter DJI SPREADING WINGS S1000+

The greatest total mass has a centrifugal sowing device $4741 \mathrm{~g}$ (design 4$)$. The smallest mass has a mechanical vertical plate precision sowing devices $1689 \mathrm{~g}$ (design 6). This will make it possible to install several sowing devices on the UAV at the same time.

\subsubsection{Research of Technological Applicability of Sowing Devices}

The decisive factors when choosing the type of sowing device will be the required technological parameters of the aerial sowing process and the parameters of the seeds used. For further research, it was decided to select a sowing device that meets the following indicators:

- $\quad$ the possibility of sowing pelleted calibrated seeds of Scots pine;

- $\quad$ the need for deepening into the surface layer;

- implementation of row sowing with exact adherence to sowing patterns.

These conditions were formulated by the authors based on the analysis performed in Sections 2.1 and 2.2 and conditions at a specific reforestation site. This is a plot of pine forest of the educational and experimental forestry of the Voronezh Forestry University, completely destroyed by the massive fires of 2010, and then cleared and restored with Scotch pine crops planted along the bottom of the furrows. Further, in the summer of 2021, young trees were completely destroyed by a repeated forest fire. Therefore, there are no wood remains and dead trees more than $2 \mathrm{~m}$ high on the site, there are expressed plow furrows, a fairly dense grassy cover has been formed in the row spacing, and the sandy soil in the rows is completely devoid of ground cover.

According to the results of a comparative assessment (Table 4), only a vacuumpneumatic vertical plate precision sowing device (design 8 ) and a mechanical-pneumatic vertical plate precision sowing device similar to it in terms of basic parameters (design 7) meet the specified technological requirements. They were chosen for further simulation studies.

If it is necessary to carry out sowing in other conditions, the evaluation table can be used to select the most suitable types of sowing devices. For example, air flow and centrifugal sowing devices can be used for continuous area sowing of small and medium seeds without the need for penetration into the surface layer. These types of sowing devices are also more widely used in agriculture. For sowing large seeds and seeds that have significant differences in size and shape, the most suitable periodically opening and roller sowing devices. 
Table 4. Assessment of applicability of sowing devices by technological characteristics.

\begin{tabular}{|c|c|c|c|c|c|c|c|c|}
\hline \multirow{2}{*}{$\begin{array}{c}\text { Criterion (Technological } \\
\text { Applicability) }\end{array}$} & \multicolumn{8}{|c|}{ 3D Concept } \\
\hline & 1 & 2 & 3 & 4 & 5 & 6 & 7 & 8 \\
\hline Precise sowing & - & - & - & - & $\mathrm{O}$ & $\mathrm{O}$ & + & + \\
\hline Row sowing & $\mathrm{O}$ & + & - & - & + & + & + & + \\
\hline Area sowing & $\mathrm{O}$ & $\mathrm{O}$ & + & + & $\mathrm{o}$ & $\mathrm{O}$ & $\mathrm{O}$ & $\mathrm{O}$ \\
\hline Deepening into the soil & - & - & - & - & - & - & + & + \\
\hline Small seeds $(1-4 \mathrm{~mm})$ & + & + & + & + & + & + & + & + \\
\hline Average seeds $(5-9 \mathrm{~mm})$ & + & $\mathrm{O}$ & $\mathrm{O}$ & $\mathrm{O}$ & - & + & + & + \\
\hline Large seeds (10 mm) & + & - & - & - & - & $\mathrm{O}$ & $\mathrm{O}$ & $\mathrm{O}$ \\
\hline $\begin{array}{l}\text { Application of seeds of } \\
\text { various shapes }\end{array}$ & + & + & + & + & - & o & - & - \\
\hline $\begin{array}{l}\text { Application of seeds of } \\
\text { different sizes }\end{array}$ & + & $\mathrm{o}$ & $\mathrm{o}$ & $\mathrm{O}$ & - & - & - & - \\
\hline
\end{tabular}

Notes: (-)—sign is absent; (o)—sign expressed moderately; (+)—sign expressed strongly; Gray color highlighting of key technological requirements and sowing devices that fully correspond to them.

\subsubsection{Description of the Design of the Investigated Sowing Device}

The model of the sowing devices (design 8 ) developed by CAD SolidWorks includes the following main elements: nozzle 1, metering body 2, metering drum 3, hopper 4, distributor 5, motor 6 (Figure 10). A design feature of the sowing device is the possibility of supplying air under pressure through the distributor 5 . This ensures the extraction of the seed and additionally imparts acceleration to it in the nozzle 1.
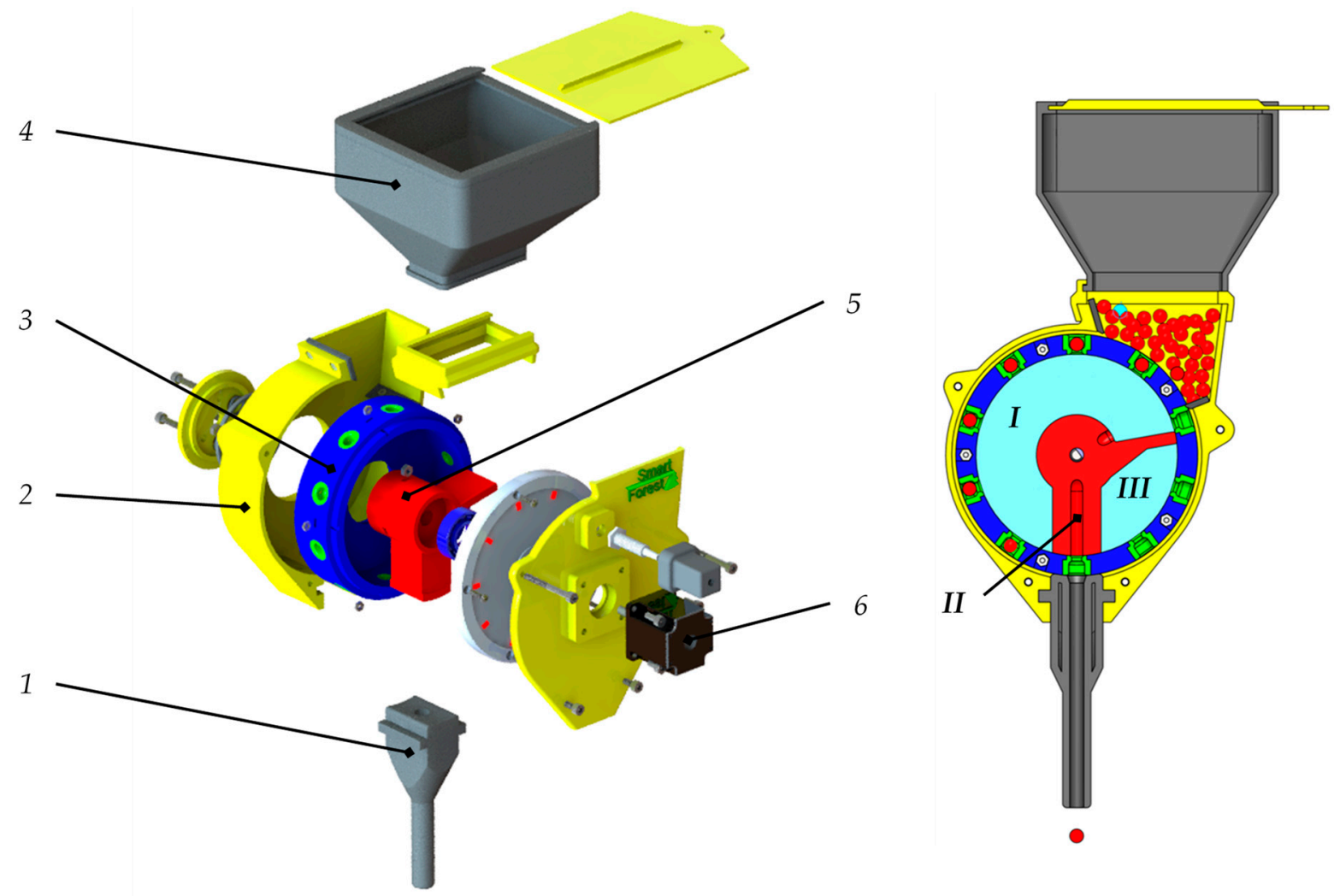

Figure 10. Structural scheme of seed sowing device: 1—nozzle; 2-metering body; 3-metering drum; 4-bunker; 5-distributor; 6-motor; I—vacuum zone; II—overpressure input channel; III—zone of atmospheric pressure. 


\subsection{Simulation of the Sowing Complex Using the Discrete Element Method (DEM)}

3.3.1. Description of the Virtual Stand for Researching the Operation of the Sowing Device

On the basis of the created 3D model using the method of discrete elements, a simulation model of the sowing device was built (Figure 11). It is able to simulate the working process for a given geometric configuration of the sowing device with a change in the diameter, quantity and nature of the interaction of the coated seeds both with each other and with the working surfaces of the sowing device. It is also possible to investigate various speed modes of rotation of the metering drum, which are determined by the flight speed and a combination of other external factors (seed moisture, deviation from sphericity, etc.).
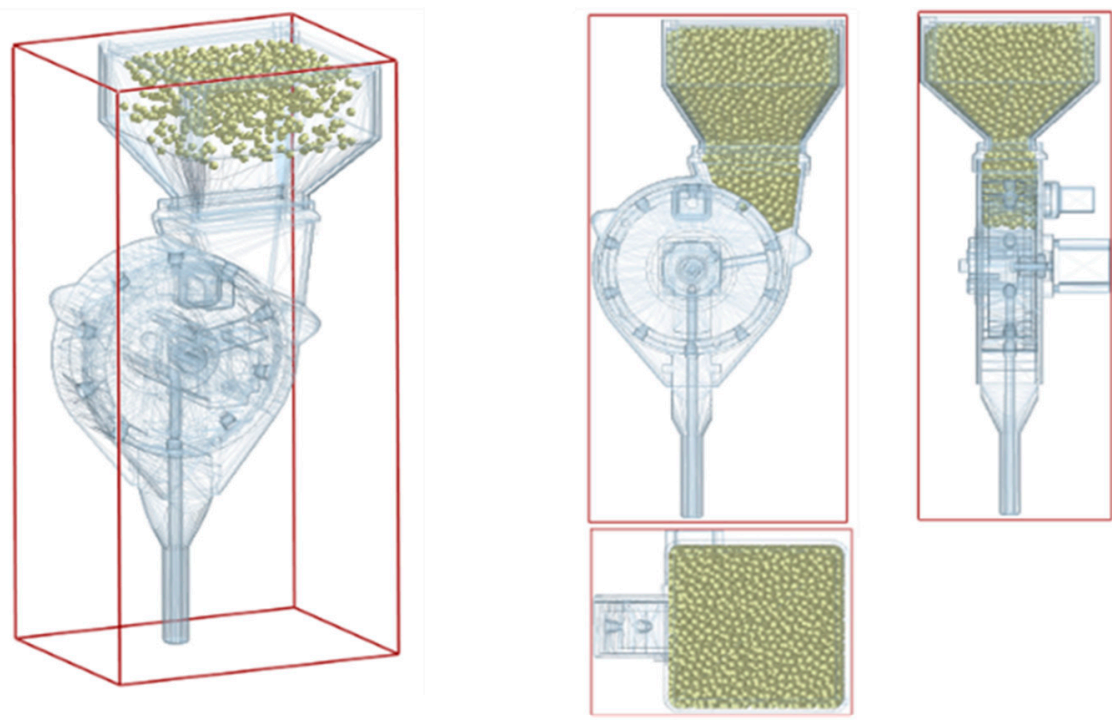

Figure 11. Calculation model of the seed sowing device.

To study the working process, the geometry of the sowing device was exported to the calculation environment in the form of a set of elementary triangles. The OBJ format was used for export. The geometry was previously simplified and combined into two elements: the metering drum and all other structural elements (elements of the metering body, seed hopper, nozzle, etc.). This allowed us to create a simpler surface mesh of elements, which significantly speeds up the calculations. In addition, the spatial position of the rotation axis of the metering drum, its rotation speed and the area of generation of particles imitating the geometry of the seeds were established.

The virtual experiment is divided into two stages: the first—filling the pelleted seeds into the hopper, the second-turning on the metering drum drive. Parameters of simulation are given in Table 5.

Table 5. Simulation parameters seed sowing device.

\begin{tabular}{cc}
\hline Parameter & Value \\
\hline Seed diameter, $\mathrm{mm}$ & $5 ; 6 ; 7$ \\
Seed density, $\mathrm{kg} / \mathrm{m}^{3}$ & 1900 \\
Seed mass, $\mathrm{g}$ & $0.124 ; 0.215 ; 0.341$ \\
Particle volume, $\mathrm{m}^{3}$ & $0.655 \times 10^{-7} ; 1.131 \times 10^{-7} ; 1.796 \times 10^{-7}$ \\
Metering drum rotation speed, $\mathrm{deg} / \mathrm{s}$ & $90 ; 135 ; 180$ \\
\hline
\end{tabular}

3.3.2. Description of the Virtual Stand for Studying the Process of Interaction of Pelleted Seed with the Soil Environment

The discrete element method also allows to study in detail the process of penetration of pelleted seeds into the target surface (soil, snow cover). Mathematical modeling of these processes requires an adequate description of a complex set of physical processes, which 
include severe deformations and discontinuity of materials. To carry out the research, a plot of the soil surface with a size of $100 \times 100 \mathrm{~mm}$ was modeled (Figure 12). The radius of soil particles in various series of experiments was taken to be $1 \mathrm{~mm}$, and an exclusively spherical shape was used. The density of particles was taken to be equal to the density of the solid phase of the soil $2500 \mathrm{~kg} \cdot \mathrm{m}^{-3}$, weight $0.011 \mathrm{~g}$. When filling with soil particles during the experiment, the formed soil layer will have a lower density, corresponding to the density of natural forest soils.
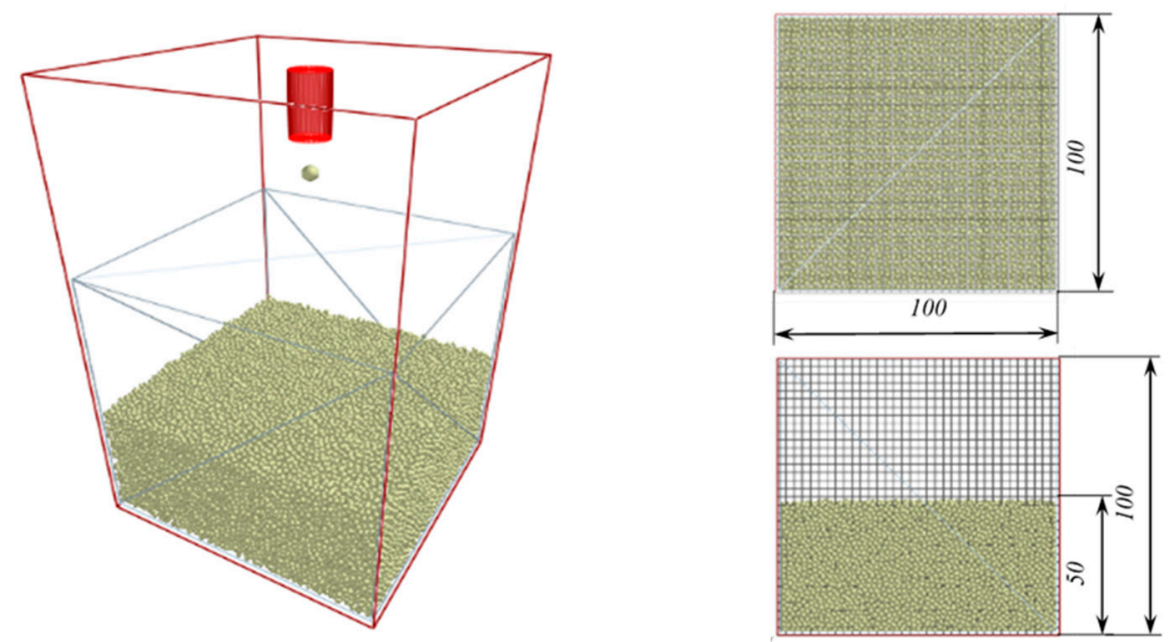

Figure 12. Virtual soil plot for seed introduction research.

The radius of the pelleted seeds was taken equal to $2.5 \mathrm{~mm}$, while the spherical shape was also used. The density of the pelleted seed was taken equal to $1900 \mathrm{~kg} \cdot \mathrm{m}^{-3}$, mass $0.124 \mathrm{~g}$.

The target soil plot was formed using filling an area of $100 \times 100 \times 100 \mathrm{~mm}$, followed by grouping of particles under the action of gravity. The resulting soil layer with a particle radius of $1 \mathrm{~mm}$ consists of 64,547 particles. The height of the reservoir is at least $50 \mathrm{~mm}$, respectively, its volume is $0.0005 \mathrm{~m}^{3}$ and the total mass of particles is $0.676 \mathrm{~kg}$. The density of the soil layer is $1352 \mathrm{~kg} \cdot \mathrm{m}^{-3}$, which corresponds to the density of forest soils. Parameters of simulation are given in Table 6.

Table 6. Simulation parameters the impact interaction of seeds with the soil environment.

\begin{tabular}{cc}
\hline Parameter & Value \\
\hline Seed diameter, $\mathrm{mm}$ & 5 \\
Soil particle diameter, $\mathrm{mm}$ & 2 \\
Soil density, $\mathrm{kg} / \mathrm{m}^{3}$ & 2500 \\
Seed density, $\mathrm{kg} / \mathrm{m}^{3}$ & 1900 \\
Seed mass, $\mathrm{g}$ & 0.124 \\
Seed volume, $\mathrm{m}^{3}$ & $0.655 \times 10^{-7}$ \\
Seed speed, $\mathrm{m} / \mathrm{s}$ & $25 ; 50 ; 75$ \\
\hline
\end{tabular}

\subsubsection{Description of the Discrete Interaction Model}

When discrete particles come into contact with each other and solid surfaces, elastic forces arise, and forces of dry and viscous friction (Figure 13). The motion of discrete elements under the action of these forces is calculated according to the laws of classical dynamics. Modeling is carried out in 3D Cartesian space $(x, y, z)$. The state of each element $E_{\mathrm{i}}$ is specified by six variables: the coordinates of its center $\left(x_{\mathrm{i}}, y_{\mathrm{i}}, z_{\mathrm{i}}\right)$ and the velocity components $\left(v_{\mathrm{xi}}, v_{\mathrm{yi}}, v_{\mathrm{zi}}\right)$. 


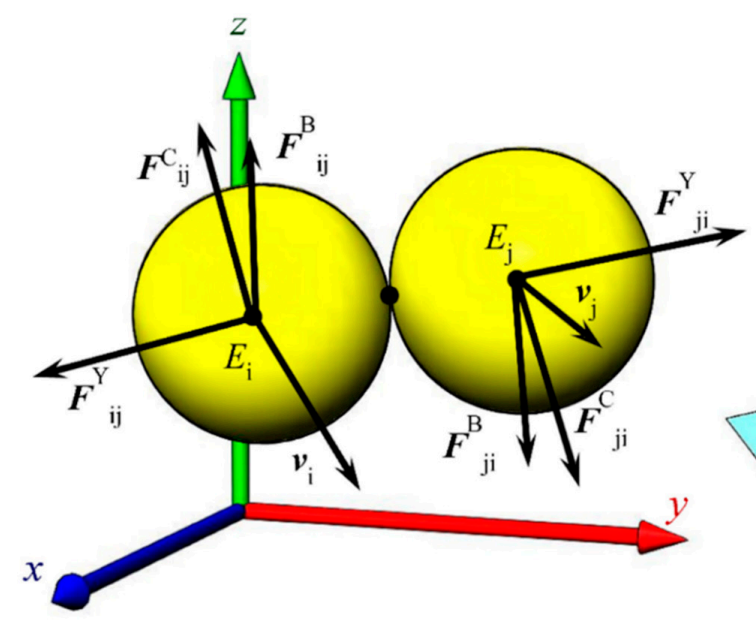

(a)

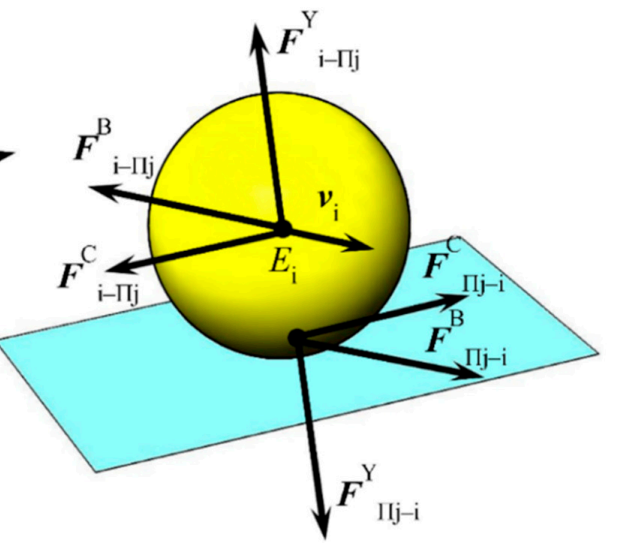

(b)

Figure 13. Schemes of force contact of elements: (a) - forces arising from the contact of two discrete elements; (b) - forces arising from the contact of the discrete element and a solid surface; $F^{\mathrm{Y}}$-elastic forces; $F^{\mathrm{C}}$ and $F^{\mathrm{B}}$ - dry and viscous friction forces.

The mathematical discrete model used is described in more detail in the author's previous publications [50].

\subsection{The Results of Simulation Modeling of the Full Load of the Hopper of the Metering Device}

In the first stage, particles were continuously generated at the level of the hopper lid to investigate the hopper capacity. The generation area was located between the inner walls of the hopper. During the experiment, the degree of filling the hopper was controlled without additional compaction of the seeds.

So, with a particle diameter of $5 \mathrm{~mm}$, the total capacity of the hopper and the throat of the sowing device was at least 7426 pieces. With an increase in diameter to 6 and $7 \mathrm{~mm}$, the capacity was 4210 and 2551 pieces, respectively (Figure 14). The total seed weight of the fully loaded hopper was 920.8, 905.2, $870.4 \mathrm{~g}$, respectively.

diameter $5 \mathrm{~mm}$

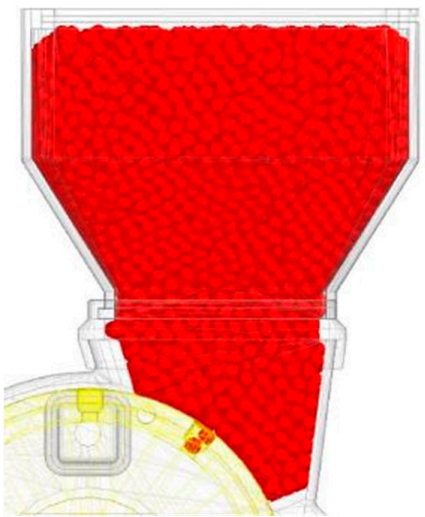

diameter $6 \mathrm{~mm}$

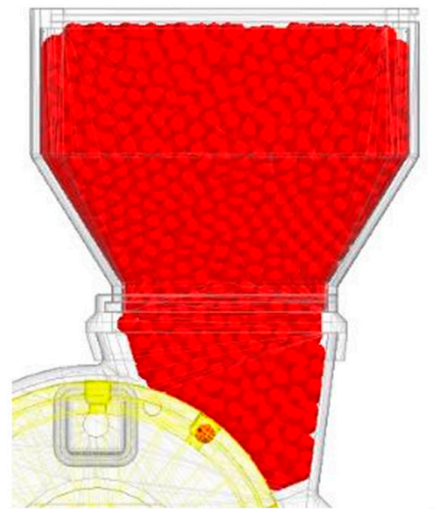

diameter $7 \mathrm{~mm}$

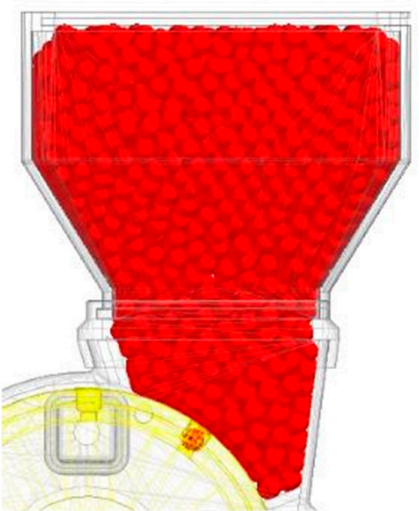

Figure 14. Simulation of the process of loading the seed hopper with pelleted seeds of various diameters.

The data obtained as a result of modeling were slightly less than the preliminary estimate data, according to which the hopper capacity was $1008 \mathrm{~g}$. The maximum difference reaches $14 \%$ for seeds with a diameter of $7 \mathrm{~mm}$. 


\subsection{DEM Simulation of the Sowing Device}

To simulate the working process of the sowing device, an incomplete hopper loading (1000 pcs) was used. This is due to the need to keep the time for calculating the model on a personal computer within acceptable limits $(6-10 \mathrm{~h})$.

Figure 15 shows the main stages of modeling the working process of the sowing device: loading the bunker; seed capture; seed extraction; dispersal of the seed.

\section{Hopper loading}

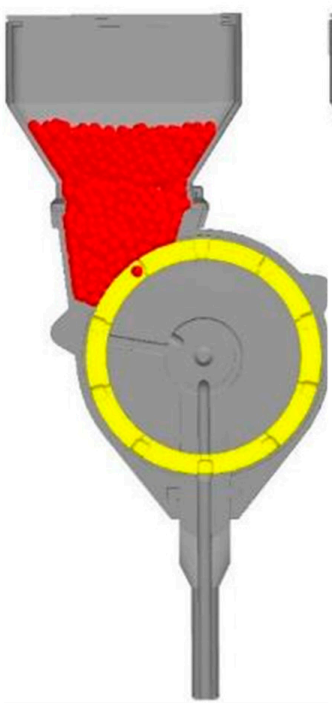

\section{Seeds capturing}

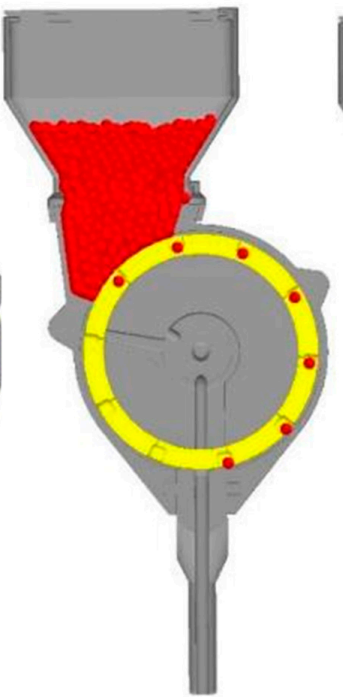

Seed extraction

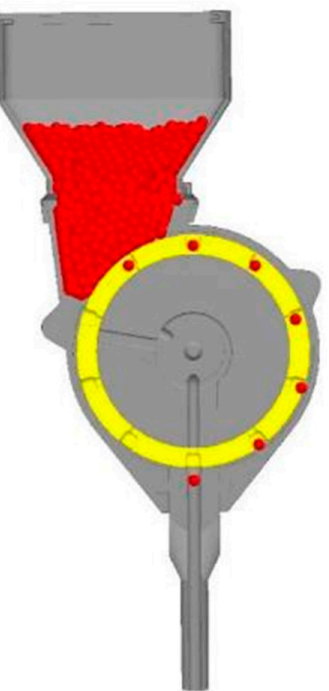

\section{Seed dispersal}

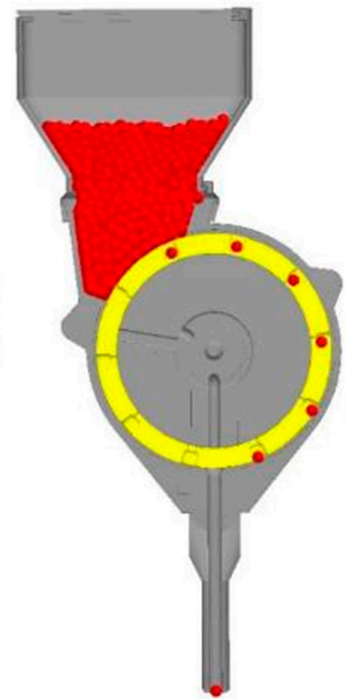

Figure 15. The main stages of simulating the operation of the seed sowing device.

As a result of the simulation, the torque on the metering drum shaft was calculated (Figure 16). Analysis of the graph shows that the average value of the torque during one working cycle (full revolution of the metering drum) is $0.129 \mathrm{Nm}$. These values are obtained for a nominal operating speed of rotation of the drum of $180 \mathrm{deg} / \mathrm{s}$ used when flying the UAV at a speed of $5 \mathrm{~m} / \mathrm{s}$ to ensure a sowing step of $1 \mathrm{~m}$. Average maximum torque values reach $0.228 \mathrm{Nm}$. Cyclically repeating peaks arise due to the growth of resistance forces at the moment the scraper removes excess seeds from the seed channel.

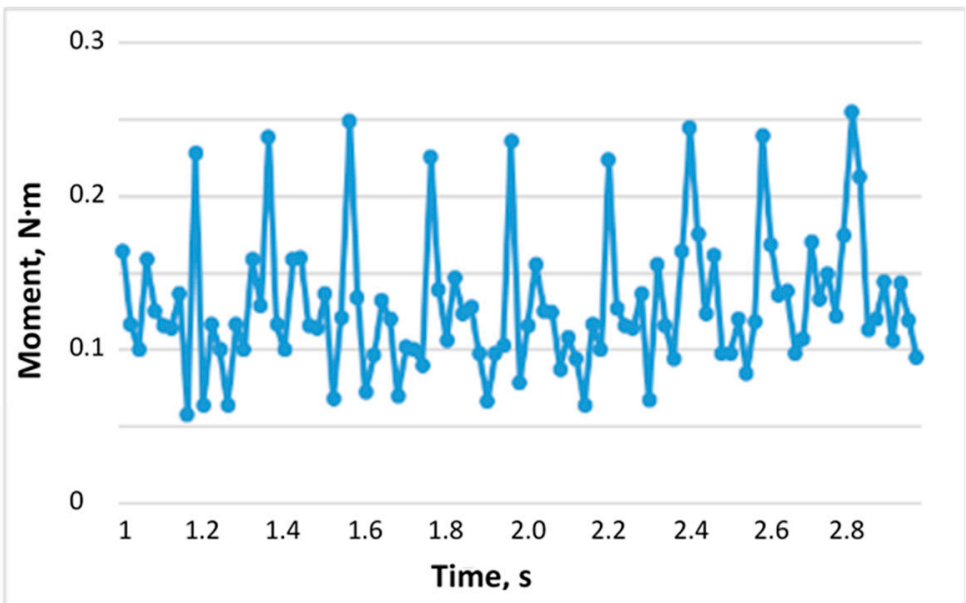

Figure 16. Torque on the metering drum shaft.

Figure 17 shows the percentage of captured seeds at different rotational speeds. Changing the rotation speed slightly reduced the stability of the capture of the seeds. With a double increase in the rotation rate from 90 to $180 \mathrm{deg} / \mathrm{s}$, the average number of missing 
seeds increased from 0.7 to $3.5 \%$. A change in the diameter of the seed with a corresponding change in the size of the seed canal did not have a noticeable effect on the number of skips.

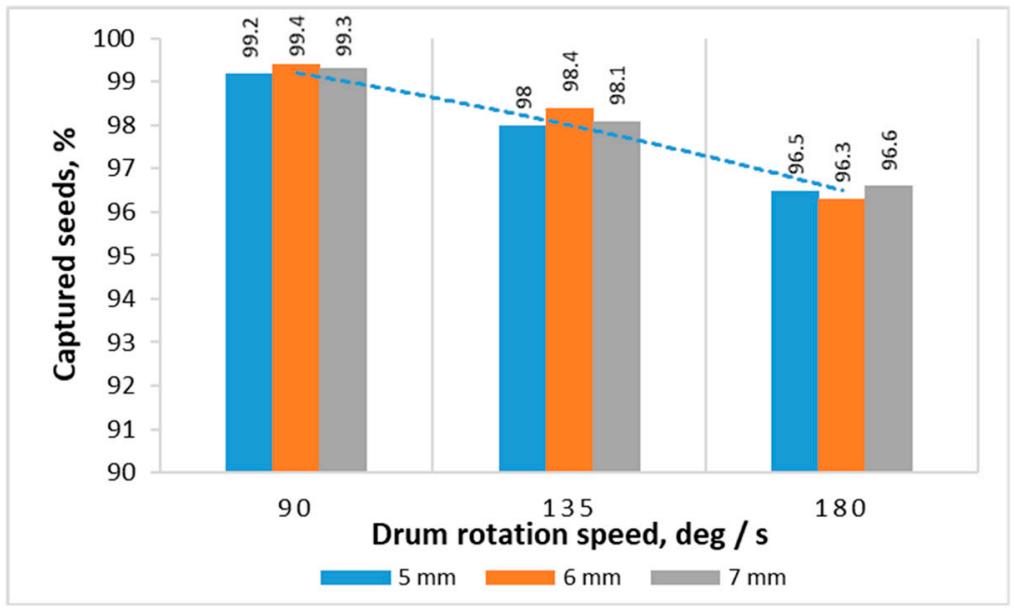

Figure 17. Sowing uniformity.

In addition, it should be noted that in order to simplify the model, the operation of the sowing device was investigated in the absence of vacuum used in the design 8 to improve the capture of the seed, that is, the working process of the sowing device of concept 7 was practically simulated.

\subsection{DEM Modeling of Interaction of Seeds and Soil Environment}

Figure 18 shows color diagrams of the central cut of the soil, demonstrating the process of penetration pelleted seed into loosely cohesive soil at flight speeds of 25,50 and $75 \mathrm{~m} / \mathrm{s}$.

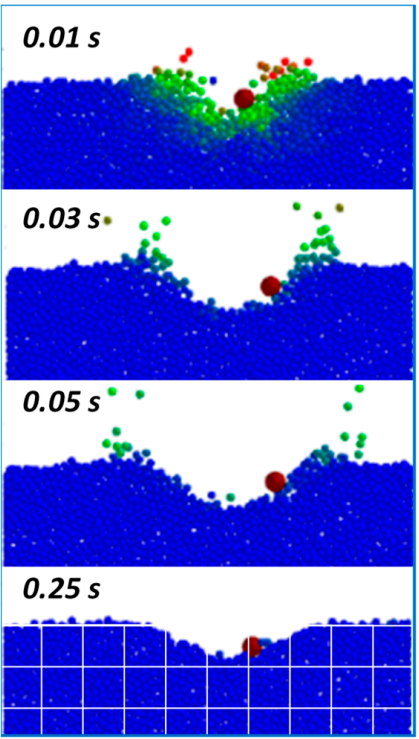

$25 \mathrm{~m} / \mathrm{s}$
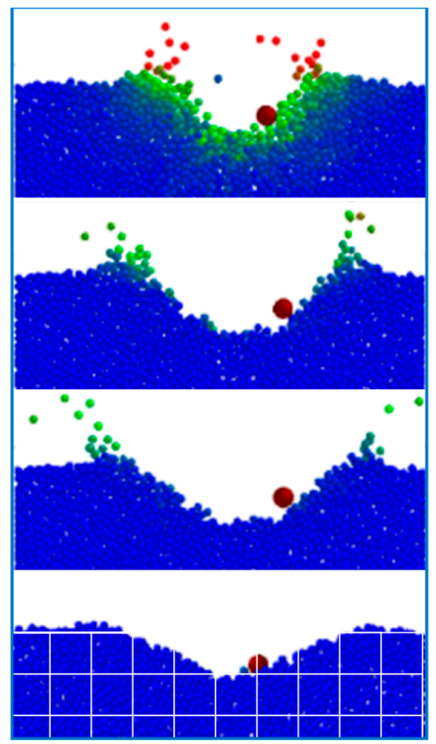

$50 \mathrm{~m} / \mathrm{s}$

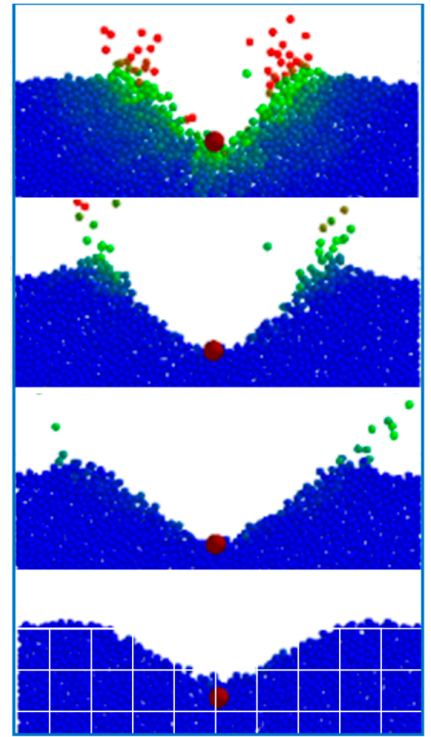

$75 \mathrm{~m} / \mathrm{s}$

Figure 18. The process of seed penetration into loosely cohesive soil at different speeds.

Analysis of the data shows that at speeds of 25 and $50 \mathrm{~m} / \mathrm{s}$, the depth of the crater is slightly greater than the depth of seed penetration. This is due to the fact that the entry of the seed into the soil does not occur vertically downwards, but at a slight angle due to the significant speed of the UAV. Therefore, there is a slight longitudinal displacement of the change upward along the wall of the formed crater. At a flight speed of $75 \mathrm{~m} / \mathrm{s}$, on the 
other hand, the penetration depth is greater than the depth of the crater, which means that the seed is completely covered with soil.

Figure 19 shows color diagrams of the central cut of the soil, demonstrating the process of penetration pelleted seed into medium cohesive soil at flight speeds of 25,50 and $75 \mathrm{~m} / \mathrm{s}$.

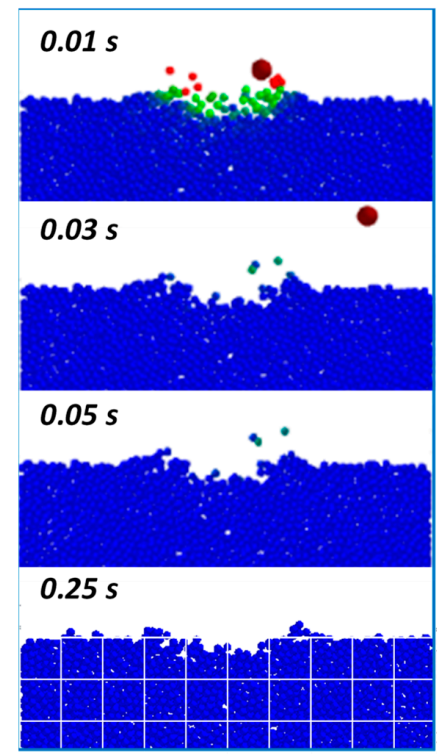

$25 \mathrm{~m} / \mathrm{s}$

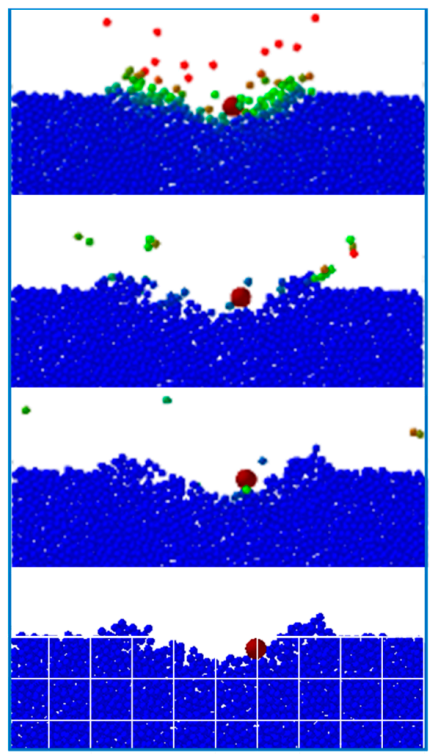

$50 \mathrm{~m} / \mathrm{s}$

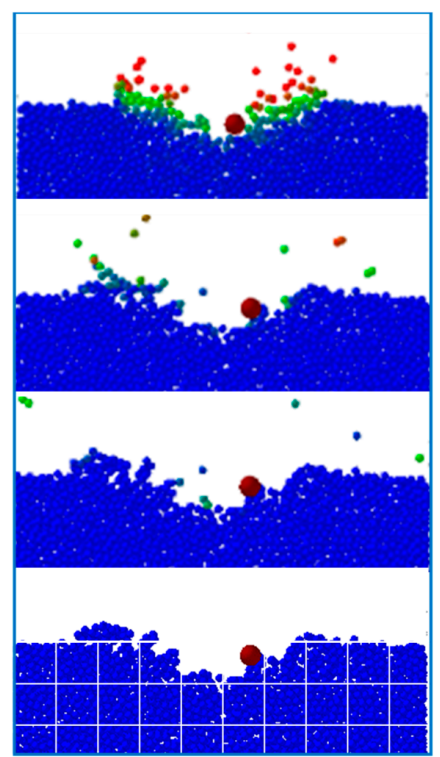

$75 \mathrm{~m} / \mathrm{s}$

Figure 19. The process of seed penetration into medium cohesive soil at different speeds.

Analysis of the data shows that at speeds of $25 \mathrm{~m} / \mathrm{s}$, the seed is ejected from the crater outside the modeling zone in all experiments. At a speed of $50 \mathrm{~m} / \mathrm{s}$, the probability of seed ejection is reduced to $10 \%$. The depth of the crater at speeds of 50 and $75 \mathrm{~m} / \mathrm{s}$ is also slightly greater than the penetration depth of the seed.

Figure 20 shows color diagrams of the central cut of the soil, demonstrating the process of penetration the pelleted seed into the cohesive soil at flight speeds of 25,50 and $75 \mathrm{~m} / \mathrm{s}$.

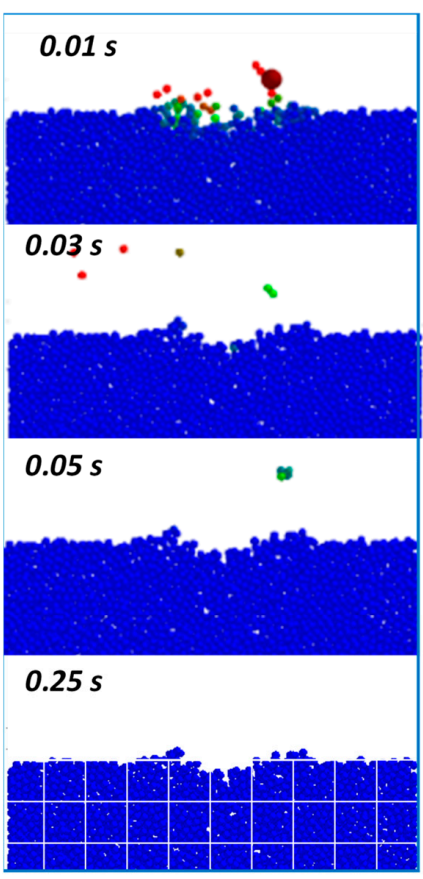

$25 \mathrm{~m} / \mathrm{s}$

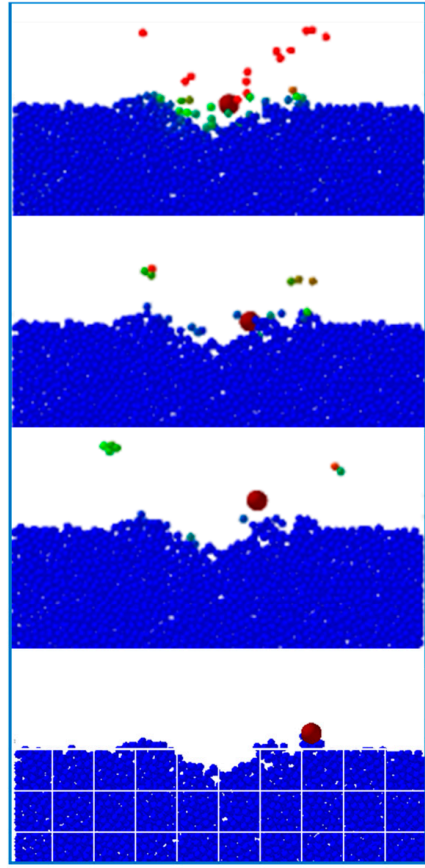

$50 \mathrm{~m} / \mathrm{s}$

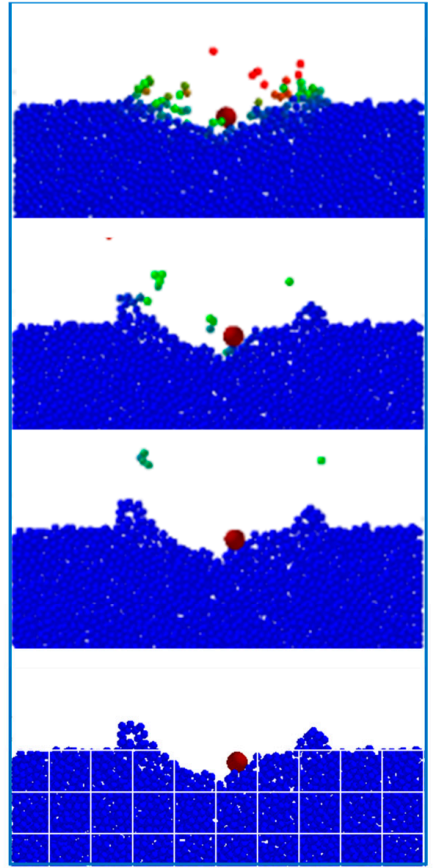

$75 \mathrm{~m} / \mathrm{s}$

Figure 20. The process of seed penetration into cohesive soil at different speeds. 
Analysis of the data shows that at speeds of $25 \mathrm{~m} / \mathrm{s}$, the seed is ejected from the crater outside the modeling zone in all experiments. At a speed of $50 \mathrm{~m} / \mathrm{s}$, the probability of seed ejection is reduced to $30 \%$ and at $75 \mathrm{~m} / \mathrm{s}$ to $10 \%$. The depth of the crater at speeds of 50 and $75 \mathrm{~m} / \mathrm{s}$ is also slightly greater than the penetration depth of the seed.

In addition, Figure 21 provides a summary of average crater depths and average penetration depths on different soil types.

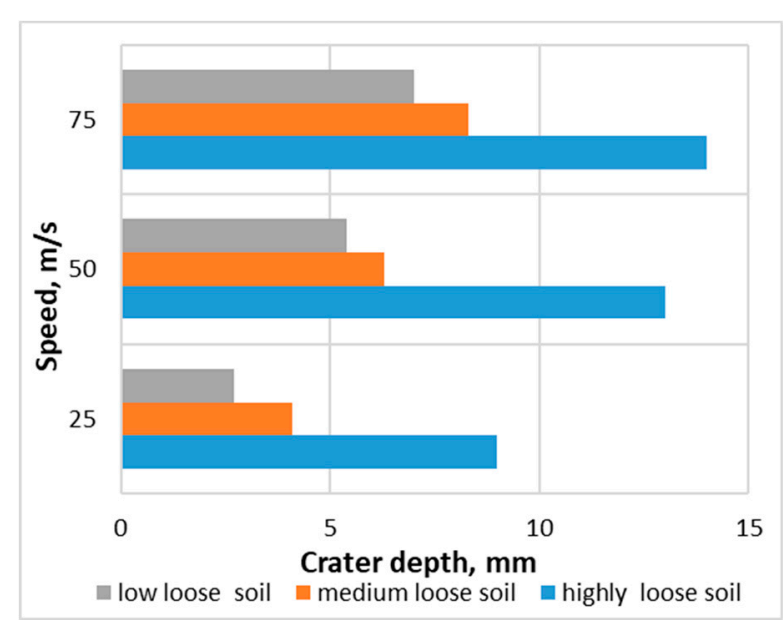

(a)

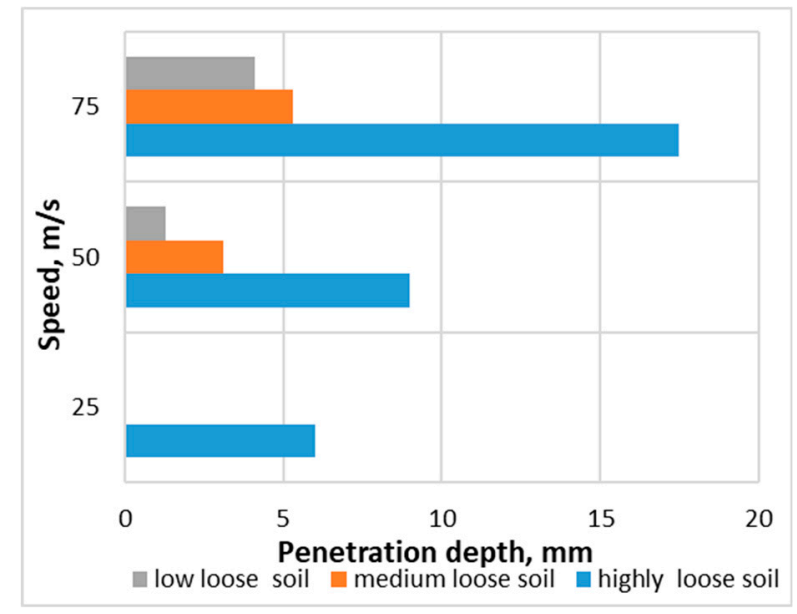

(b)

Figure 21. Average crater depths (a) and penetration depths of pelleted seeds (b) on different types of soils.

Thus, the following high-speed operating modes of the sowing device can be recommended.

On loose and loosely cohesive soils (sandy soils), an entry speed of $50 \mathrm{~m} / \mathrm{s}$ is sufficient for almost $100 \%$ penetration into the surface layer without noticeable displacement of the pelleted seed. Even at a speed of $25 \mathrm{~m} / \mathrm{s}$ (in fact, it is achieved with a free fall from heights of more than $30 \mathrm{~m}$ ), there is a slight displacement practically without carrying out beyond the boundaries of the formed crater.

On medium cohesive soils at a speed of $50 \mathrm{~m} / \mathrm{s}$, stable seed penetration is not ensured. The probability of its ejection is about $10 \%$. At speeds of $75 \mathrm{~m} / \mathrm{s}$, almost $100 \%$ penetration into the surface layer is ensured without noticeable displacement of the seed.

On cohesive soils at speeds of $25 \mathrm{~m} / \mathrm{s}$, the seed is always ejected from the crater over a considerable distance. At a speed of $50 \mathrm{~m} / \mathrm{s}$, the probability of seed ejection is reduced to $30 \%$ and at $75 \mathrm{~m} / \mathrm{s}$ to $10 \%$.

It should also be noted that penetration into the soil layer is observed only on loosely soils, that is, the seed is covered by soil particles from the sides and top. In the case of penetration of medium cohesive and cohesive soils, there may be only slight lateral coverage of the seed with soil particles or being on the surface, but within the formed crater.

\subsection{Creation of an Experimental Sample of the Sowing Device and the Study of Its Mass Characteristics}

Since, in accordance with the technological requirements, two similar sowing devices concept 7 and concept 8 were selected, we will compare them for the final selection of a sample for production according to the following criteria:

- comparability of technological parameters;

- mass characteristics;

- $\quad$ ease of manufacture and accuracy requirements;

- manufacturability of the design and the possibility of using it for the manufacture of 3D printing;

- operational reliability. 
In terms of mass characteristics, the sowing complex of concept 7 has a significant advantage. This is due to the absence of a vacuum seeds capture system, which ensured a decrease in weight from 4423 (concept 8) to 3116 (concept 7).

In terms of technological parameters, the sowing devices are also quite close. Concept 8 has some advantage in stability of the capture of seeds, but it is not very significant. This is confirmed by the results of virtual experiments, in which, due to the complexity, the effect of vacuum was not simulated, that is, the working process of the sowing devices of concept 7 was practically simulated.

Concept 7 has a significant advantage in terms of simplicity of manufacture, since it does not require maintaining the vacuum, which requires significant accuracy in the manufacture of the metering drum and distributor, as well as their mutual positioning.

In terms of manufacturability, the concepts are comparable, however, when used for 3D printing, concept 8 will require additional processing of the metering drum and distributor.

In terms of operational reliability, concept 7 has a significant advantage. This is due to the absence of the need to maintain the tightness of the inner cavity of the drum, which provides the possibility of self-cleaning, quick disassembly, and the ability to visually check the performance of all elements.

To confirm the mass characteristics and carry out experimental studies, a full-size experimental sample of the sowing device of concept 7 was made. All the main elements were manufactured using extruder 3D printing (Figure 22).
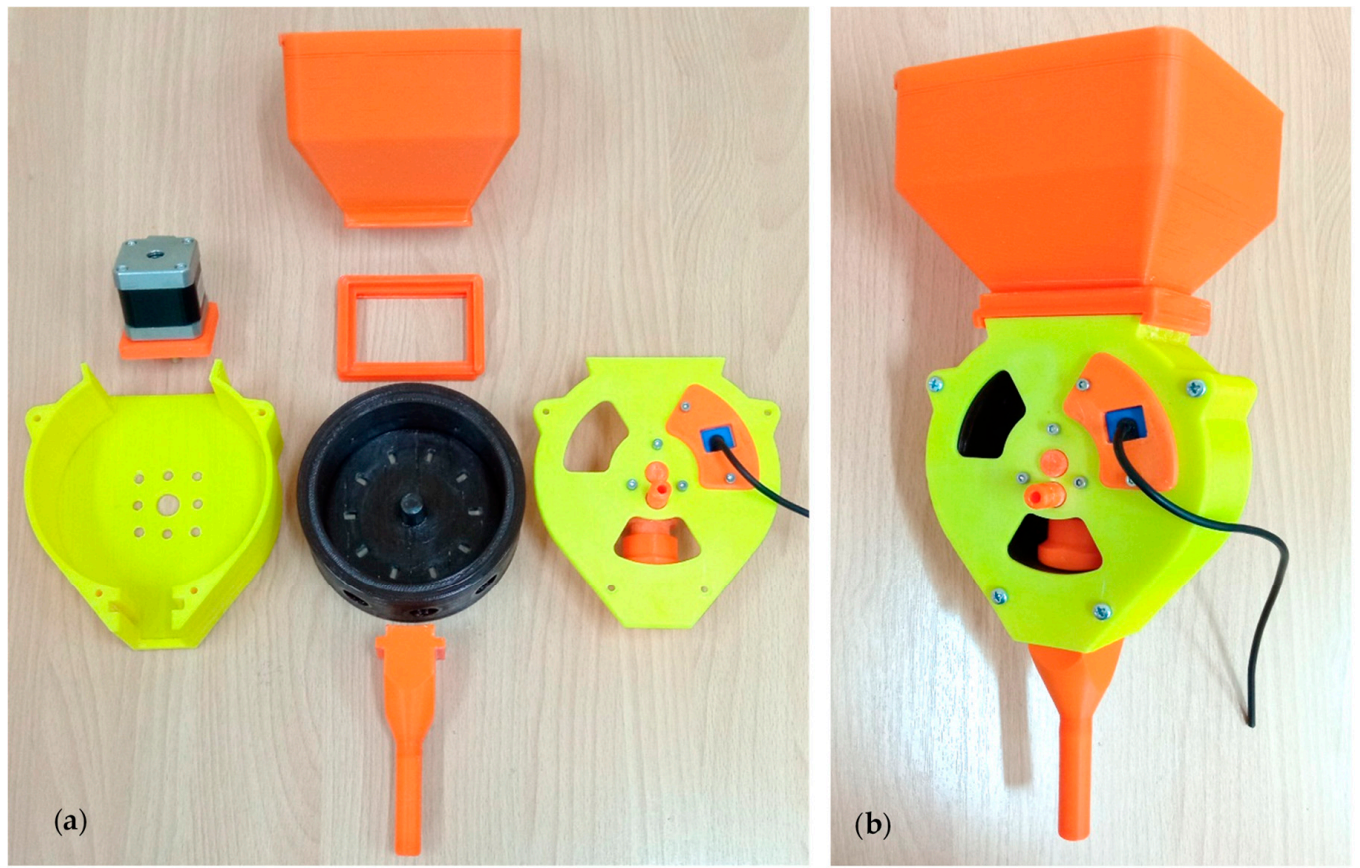

Figure 22. Experimental sowing device: (a) Partially disassembled; (b) Fully assembled.

Next, a study of the mass characteristics of the fully assembled sowing device was carried out (Figure 23a). The mass of the model was $880 \mathrm{~g}$, which is $84 \mathrm{~g}$ less than the mass of his 3D model equal to $964 \mathrm{~g}$. Such an almost $10 \%$ decrease in masses is associated with the use of incomplete filling of massive parts of the elements of the sowing device that do not experience significant loads (Figure 23b). 
3D model mass $964 \mathrm{~g}$
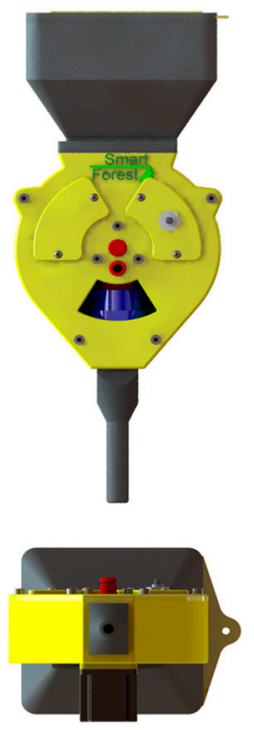

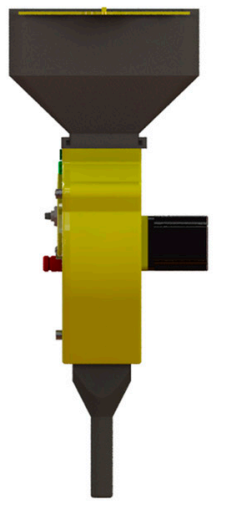

(a)
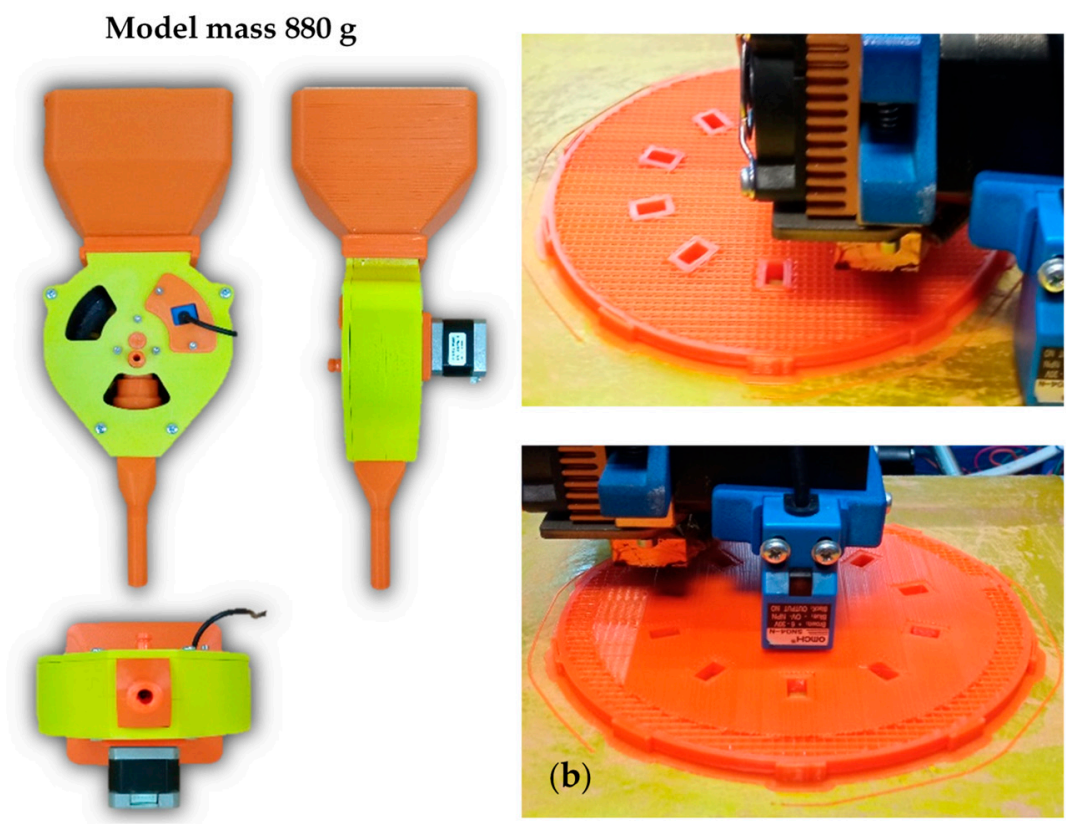

Figure 23. Experimental sowing device: (a) Comparison of mass with 3D model; (b) Production of a metering drum with partial filling.

\section{Conclusions}

The purpose of this study was to develop new, original sowing device designed for installation on UAVs and perform complex studies using 3D CAD. For this, the existing designs of the metering system and the seed distribution system used both on tractor seeders and on UAVs were analyzed. In addition, the main types of seed used for aerial sowing were determined. Based on the analysis performed, parametric 3D models of eight different sowing device were created and comparative studies of their mass characteristics were carried out. According to the technological parameters specified by the authors, required for reforestation in a specific area, the most suitable type of sowing device was selected and a description of its design was given.

The discrete element method (DEM) was used to carry out simulation studies of the working process of the selected sowing device. The results of modeling the process of filling the hopper showed that with a particle diameter of $5 \mathrm{~mm}$, the total capacity of the hopper and the throat of the sowing device was at least 7426 pcs. With an increase in diameter to 6 and $7 \mathrm{~mm}$, the capacity was 4210 and 2551 seeds, respectively. The total seed mass of the fully loaded hopper was $920.8,905.2,870.4 \mathrm{~g}$.

The results of simulating the working process of the sowing device showed that a change in the rotation speed slightly reduced the stability of the capture of seeds. With a double increase in the rotation rate from 90 to $180 \mathrm{deg} / \mathrm{s}$, the average number of missing seeds increased from 0.7 to $3.5 \%$. This is due to the deterioration in the capture and extraction of seeds due to the fact that the experiment did not reproduce the influence of vacuum and excess pressure. In further studies, it is planned to carry out joint DEM-CFD modeling, which will most fully reproduce the operation of the sowing device. Changing the seed diameter did not significantly affect the number of skips.

The average value of the torque during one working cycle was also investigated. It is $0.129 \mathrm{Nm}$. These values were obtained for a drum rotation speed of $180 \mathrm{deg} / \mathrm{s}$ used during a UAV flight at a speed of $5 \mathrm{~m} / \mathrm{s}$ and providing a sowing step of $1 \mathrm{~m}$.

The study of the impact interaction of a spherical pelleted seed with the soil environment made it possible to determine the possibility of seed penetration depending on the speed of its movement and the degree of cohesion of the soil environment. It has been found that on loosely cohesive soils, a seed speed of $50 \mathrm{~m} / \mathrm{s}$ is sufficient for almost $100 \%$ 
penetration into the surface layer without noticeable seed movement. On medium cohesive soils with a seed speed of $50 \mathrm{~m} / \mathrm{s}$, the probability of ejection is about $10 \%$. At a speed of $75 \mathrm{~m} / \mathrm{s}$, almost $100 \%$ penetration into the surface layer is achieved. On cohesive soils at a speed of $25 \mathrm{~m} / \mathrm{s}$, seeds are always thrown out of the crater over a considerable distance. At a speed of $50 \mathrm{~m} / \mathrm{s}$, the probability of an ejection is reduced to $30 \%$, and at $75 \mathrm{~m} / \mathrm{s}$ to $10 \%$.

An experimental sample of a sowing device was made using extruder 3D printing. Its mass was $880 \mathrm{~g}$, which is $84 \mathrm{~g}$ less than the mass of its 3D model equal to $964 \mathrm{~g}$. This almost $10 \%$ weight reduction is associated with the use of incomplete filling of massive parts of the elements of the sowing device, which do not experience significant loads.

In order to increase the reliability of the model of the interaction of the seed with the soil environment, in the future, it will be necessary to take into account the speed of rotation of the seed, especially if its shape differs from spherical, and the granulometric composition of the soil. Another important feature that requires study is the possibility of destruction of seeds and their artificial cover, which is associated with their limited strength. In addition, it is necessary to investigate the cases of interaction with soil environment with physical properties uneven in depth. For example, the presence of a more durable surface layer, the presence on the surface of forest litter, vegetation cover, etc.

In further studies, it will be possible to carry out studies of other concepts sowing device according to the method used, as well as create new designs through a combination of various metering and distribution mechanisms.

The final stage of this study should be a field experiment on aerial sowing, as well as a study of the dynamics of survival and growth of trees obtained from pelleted seeds. This will bring the highly efficient technology of aerial sowing with the use of UAVs to the level of industrial reforestation and thereby help to slow down the processes of climate change.

\section{Patents}

The patent for the investigated sowing device was obtained on 11 November 2019 (concept 8), application number PI2020005912. The name of the invention is "Seeder for $\mathrm{UAV}^{\prime \prime}$. In the process of writing this work, a patent application for the sowing device of concept 7 was also formed and filed.

Author Contributions: Conceptualization, M.L., L.B. and D.D.; methodology, M.L.; investigation, M.L.; writing—original draft preparation, M.L., L.B. and D.D.; writing-review and editing, M.L., L.B. and D.D.; visualization, M.L.; supervision, M.L.; project administration, M.L. All authors have read and agreed to the published version of the manuscript.

Funding: This research received no external funding.

Data Availability Statement: Data sharing not applicable.

Conflicts of Interest: The authors declare no conflict of interest.

\section{References}

1. Mohan, M.; Richardson, G.; Gopan, G.; Aghai, M.M.; Bajaj, S.; Galgamuwa, G.A.P.; Vastaranta, M.; Arachchige, P.S.P.; Amorós, L.; Corte, A.P.D.; et al. UAV-supported forest regeneration: Current trends, challenges and implications. Remote Sens. 2021, 13, 2596. [CrossRef]

2. Novikov, A.I.; Ersson, B.T. Aerial seeding of forests in Russia: A selected literature analysis. IOP Conf. Ser. Earth Environ. Sci. 2019, 226, 012051. [CrossRef]

3. Order of the Ministry of Natural Resources and Environment of the Russian Federation Dated 04.12.2020 No. 1014. Available online: http:/ / publication.pravo.gov.ru/Document/View /0001202012180052?index=1\&rangeSize=1 (accessed on 18 October 2021).

4. Rudoy, E.V.; Petukhova, M.S.; Ryumkin, S.V.; Truflyak, E.V.; Kurchenko, N.Y. Scientifically Grounded Forecast of the Development of Precision Farming in Russia; ITS NGAU «Zolotoy kolos»: Novosibirsk, Russia, 2021.

5. JetSeed Granule Spreading System-XAG. Available online: https://www.xa.com/en/jetseed (accessed on 23 September 2021).

6. Bacherikov, I.V.; Novikov, A.I.; Petrishchev, E.P. Discrete seed feeder designing for mobile apparatus: Early results for Pinus Sylvestris 1. species. Inventions 2021, 6, 14. [CrossRef]

7. Drone Granula Spreadying System China Manufacturer. Available online: https://www.jmrdrone.com/agriculture-drone-parts/ 57412215.html (accessed on 23 July 2021). 
8. Amorós, L.; Ledesma, J. Aerial robotics for forest management and seeding. Refor. Biodivers. Carbon Capture Livelihoods 2015, 151, $10-17$.

9. Murray, J.R.; Tullberg, J.N.; Basnet, B.B. Planters and their components. Types, attributes, functional requirements, classification and description. Aust. Cent. Int. Agric. Res. 2006. [CrossRef]

10. Huang, X.; Zhang, S.; Luo, C.; Li, W.; Liao, Y. Design and experimentation of an aerial seeding system for rapeseed based on an air-assisted centralized metering device and a multi-rotor crop protection UAV. Appl. Sci. 2020, 10, 8854. [CrossRef]

11. UGS-2G-Specifications. Available online: https://www.cfr-innovations.com/product-page/ugs-2g (accessed on $23 \mathrm{July} 2021$ ).

12. User Guide T Series Spreading System. Available online: http:/ / www.dji.com (accessed on 23 September 2021).

13. OSA HEXA S-1. Available online: https:/ / bozon.aero/cat/koptery-c1/osa-hexa-s-1-i3.html (accessed on 14 October 2021).

14. Reforestation. AirSeed Technologies. Australia. Available online: https://www.airseedtech.com/ (accessed on 16 July 2021).

15. Dendra Systems: Automation and Intelligence for the Natural World. Available online: https://www.dendra.io/ (accessed on 16 July 2021).

16. Tree-Planting Drones to Speed Up Reforestation Efforts. Available online: https://newatlas.com/tree-planting-dronesdroneseed/45259/ (accessed on 23 September 2021).

17. Flash Forest. Available online: https:/ / flashforest.ca/ (accessed on 14 September 2021).

18. Tylek, P.; Demidov, D.N.; Lysych, M.N.; Petrishchev, E.P.; Maklakova, E.A. The features designed of mechatronic system of adaptive hopper's feeder: Case study for Scots pine seeds morphometry. IOP Conf. Ser. Earth Environ. Sci. 2020, 595, 012054. [CrossRef]

19. JetSeed Система разбрасывания гранул-XAG. Available online: https:/ / xag.com.ru/jetseed (accessed on 23 July 2021).

20. Система распыленияT Series Spreading System 2.0 купить в официальном магазине с доставкой. Available online: https: / / 4vision.ru/products / sistema-raspyleniya-mg-series-spreading-system-20.html (accessed on 23 July 2021).

21. Rapid Reforestation / DroneSeed. Available online: https:// droneseed.com/ (accessed on 1 October 2021).

22. Bangura, K.; Gong, H.; Deng, R.; Tao, M.; Liu, C.; Cai, Y.; Liao, K.; Liu, J.; Qi, L. Simulation analysis of fertilizer discharge process using the Discrete Element Method (DEM). PLoS ONE 2020, 15, e0235872. [CrossRef]

23. Huang, Y.; Wang, B.; Yao, Y.; Ding, S.; Zhang, J.; Zhu, R. Parameter optimization of fluted-roller meter using discrete element method. Int. J. Agric. Biol. Eng. 2018, 11, 65-72. [CrossRef]

24. Marcinkiewicz, J.; Selech, J.; Staszak, Ż.; Gierz, Ł.; Ulbrich, D.; Romek, D. DEM simulation research of selected sowing unit elements used in a mechanical seeding drill. MATEC Web Conf. 2019, 254, 02021. [CrossRef]

25. Wu, Z.; Li, M.; Lei, X.; Wu, Z.; Jiang, C.; Zhou, L.; Ma, R.; Chen, Y. Simulation and parameter optimisation of a centrifugal rice seeding spreader for a UAV. Biosyst. Eng. 2020, 192, 275-293. [CrossRef]

26. Coetzee, C.J.; Lombard, S.G. Discrete element method modelling of a centrifugal fertiliser spreader. Biosyst. Eng. 2011, 109, 308-325. [CrossRef]

27. Van Liedekerke, P.; Tijskens, E.; Dintwa, E.; Rioual, F.; Vangeyte, J.; Ramon, H. DEM simulations of the particle flow on a centrifugal fertilizer spreader. Powder Technol. 2009, 190, 348-360. [CrossRef]

28. Li, S.; Student, M.; District, H. The modal analysis and simulation of gramineae-leguminous mixed seeding based on EDEM. ASABE Annu. Int. Meet. Pap. 2015, 152189675, 1-5.

29. Lai, Q.; Hu, Z.; Xing, J.; Ma, W. Simulation and verification for seed-filling performance of cell wheel precision seed metering device based on discrete element method. MATEC Web Conf. 2018, 169, 01035. [CrossRef]

30. Li, Y.S.P.S.; Xing, S.; Li, S.; Liu, L.; Zhang, X.; Song, Z.; LI, F. Seeding performance simulations and experiments for a spoon- wheel type precision cottonseed-metering device based on EDEM. Mech. Eng. Sci. 2020, 2, 2. [CrossRef]

31. Woo, S.M.; Uyeh, D.D.; Sagong, M.S.; Ha, Y.S. Development of seeder for mixed planting of corn and soybeans. Int. J. Agric. Biol. Eng. 2017, 10, 95-101.

32. Hongxin, L.; Lifeng, G.; Lulu, F.; Shifa, T. Study on multi-size seed-metering device for vertical plate soybean precision planter. Int. J. Agric. Biol. Eng. 2015, 8, 1-8.

33. Jinwu, W.; Han, T.; Jinfeng, W.; Xin, L.; Huinan, H. Optimization design and experiment on ripple surface type pickup finger of precision maize seed metering device. Int. J. Agric. Biol. Eng. 2017, 10, 61-71.

34. Hong, F.; Changrui, W.; Cong, J. Development of digital design software platform AgriDEM for agricultural machinery parts. Trans. Chinese Soc. Agric. Eng. 2017, 33, 1-9.

35. Han, D.; Zhang, D.; Jing, H.; Yang, L.; Cui, T.; Ding, Y.; Wang, Z.; Wang, Y.; Zhang, T. DEM-CFD coupling simulation and optimization of an inside-filling air-blowing maize precision seed-metering device. Comput. Electron. Agric. 2018, 150, 426-438. [CrossRef]

36. Lei, X.; Liao, Y.; Zhang, Q.; Wang, L.; Liao, Q. Numerical simulation of seed motion characteristics of distribution head for rapeseed and wheat. Comput. Electron. Agric. 2018, 150, 98-109. [CrossRef]

37. Lysych, M.N. Review of numerical methods for modeling the interaction of soil environments with the tools of soil tillage machines. J. Phys. Conf. Ser. 2019, 1399, 044014. [CrossRef]

38. Ucgul, M.; Saunders, C.; Li, P.; Lee, S. Analyzing the mixing performance of a rotary spader using digital image processing and discrete element modelling (DEM). Comput. Electron. Agric. 2018, 151, 1-10. [CrossRef]

39. Zhao, H.; Li, H.; Ma, S.; He, J.; Wang, Q.; Lu, C.; Zheng, Z. The effect of various edge-curve types of plain-straight blades for strip tillage seeding on torque and soil disturbance using DEM. Soil Tillage Res. 2020, 202, 104674. [CrossRef] 
40. Gong, H.; Zeng, Z.; Qi, L. A discrete element model of seed-soil dynamics in soybean emergence. Plant Soil 2019, 437, 439-454. [CrossRef]

41. Zhou, H.; Chen, Y.; Sadek, M.A. Modelling of soil e seed contact using the Discrete Element Method (DEM). Biosyst. Eng. 2014, 121, 56-66. [CrossRef]

42. Ding, S.; Bai, L.; Yao, Y.; Yue, B.; Fu, Z.; Zheng, Z.; Huang, Y. Discrete element modelling (DEM) of fertilizer dual-banding with adjustable rates. Comput. Electron. Agric. 2018, 152, 32-39. [CrossRef]

43. Boudet, J.F.; Amarouchene, Y.; Kellay, H. Dynamics of impact cratering in shallow sand layers. Phys. Rev. Lett. 2006, 96, 1-4. [CrossRef] [PubMed]

44. De Vet, S.J.; De Bruyn, J.R. Shape of impact craters in granular media. Phys. Rev. E Stat. Nonlinear Soft Matter Phys. 2007, 76, 1-6. [CrossRef]

45. Goldman, D.I.; Umbanhowar, P. Scaling and dynamics of sphere and disk impact into granular media. Phys. Rev. E Stat. Nonlinear Soft Matter Phys. 2008, 77, 1-14. [CrossRef]

46. Royer, J.R.; Corwin, E.I.; Eng, P.J.; Jaeger, H.M. Gas-mediated impact dynamics in fine-grained granular materials. Phys. Rev. Lett. 2007, 99, 99-102. [CrossRef]

47. Wu, S.M.; Zhu, H.P.; Yu, A.B.; Zulli, P. Numerical investigation of crater phenomena in a particle stream impact onto a granular bed. Granul. Matter 2007, 9, 7-17. [CrossRef]

48. Ye, X.; Wang, D.; Zheng, X. Influence of particle rotation on the oblique penetration in granular media. Phys. Rev. 2012, 061304, 1-12. [CrossRef] [PubMed]

49. Wada, K.; Senshu, H.; Matsui, T. Numerical simulation of impact cratering on granular material. Icarus 2006, 180, 528-545. [CrossRef]

50. Lysych, M.N. Computer simulation of the process soil treatment by tillage tools of soil processing machines. Comput. Res. Model. 2020, 12, 607-627. [CrossRef] 